\title{
Development and Experimental Investigation of Stirling-type Pulse Tube Refrigerator (PTR) below 20 K; Cold Compressor and Colder Expander
}

Jiho Park

Cryogenic Engineering Laboratory, Division of Mechanical Engineering, School of Mechanical, Aerospace and Systems Engineering,

Korea Advanced Institute of Science and Technology,

291, Daehak-ro, Yuseong-gu, Daejeon, 34141, Republic of Korea

Tel.: +82-42-350-3079

Fax: $+82-42-350-8207$

jh8809@kaist.ac.kr

Sangkwon Jeong (corresponding author)

Cryogenic Engineering Laboratory, Division of Mechanical Engineering,

School of Mechanical, Aerospace and Systems Engineering,

Korea Advanced Institute of Science and Technology,

291, Daehak-ro, Yuseong-gu, Daejeon, 34141, Republic of Korea

Tel.: +82-42-350-3039

Fax: +82-42-350-8207

skjeong@kaist.ac.kr

Jeongmin Cha

Cryogenic Engineering Laboratory, Division of Mechanical Engineering, 
School of Mechanical, Aerospace and Systems Engineering,

Korea Advanced Institute of Science and Technology,

291, Daehak-ro, Yuseong-gu, Daejeon, 34141, Republic of Korea

Tel.: +82-42-350-3079

Fax: +82-42-350-8207

chachadoncha@kaist.ac.kr 


\begin{abstract}
This research paper focuses on the experimental investigation of the Stirling-type pulse tube refrigerator with cold compression concept. Due to this innovative feature, the pulse tube refrigerator can reach lower temperature effectively other typical single-stage Stirling-type pulse tube refrigerators. The experiment as a proof of concept is carried out to demonstrate the capability of the pulse tube refrigerator operating between $80 \mathrm{~K}$ and $20 \mathrm{~K}$. The cold linear compressor, which is submerged in a liquid nitrogen bath, produces cold mass flow with the efficiency of $85 \%$ for all the frequencies. At the lowest temperature part of the pulse tube refrigerator, the no-load temperature of $18.7 \mathrm{~K}$ is recorded and the cooling power of $0.4 \mathrm{~W}$ is measured at $20 \mathrm{~K}$. The experimental results are analyzed in dynamic and thermal aspects by using of the numerical model. The model can well explain how much losses are distributed in the system.
\end{abstract}

Keywords: cryocooler, pulse tube refrigerator (PTR), Stirling-type, cold-compression, linear compressor 


\begin{tabular}{|c|c|c|}
\hline \multicolumn{3}{|c|}{ Nomenclature } \\
\hline$A_{p}$ & cross-sectional area of piston head & Greek symbols \\
\hline & $\left(\mathrm{m}^{2}\right)$ & $\alpha \quad$ thermal diffusivity $\left(\mathrm{m}^{2} \mathrm{~s}^{-1}\right)$ \\
\hline$k_{m}$ & mechanical stiffness $\left(\mathrm{N} \mathrm{m}^{-1}\right)$ & $\eta_{\text {comp. }} \quad$ compression efficiency (-) \\
\hline$k_{g}$ & gas spring stiffness $\left(\mathrm{N} \mathrm{m}^{-1}\right)$ & $\tau \quad$ period $(\mathrm{s})$ \\
\hline$K_{E}$ & thrust constant $\left(\mathrm{N} \mathrm{A}^{-1}\right)$ & $\omega \quad$ angular frequency $\left(\mathrm{rad} \mathrm{s}^{-1}\right)$ \\
\hline$c_{m}$ & mechanical damping ( $\mathrm{Pa} \mathrm{s}$ ) & \\
\hline$c_{g}$ & gas damping ( $\mathrm{Pa} \mathrm{s})$ & All the phase angles below are expressed in the \\
\hline$f$ & operating frequency $(\mathrm{Hz})$ & form of relative phase angle to that of the input \\
\hline$f_{n}$ & resonant frequency $(\mathrm{Hz})$ & current. \\
\hline$I$ & current $(\mathrm{A})$ & \\
\hline$I_{0}$ & peak current $(\mathrm{A})$ & relative phase angle of $V\left({ }^{\circ}\right)$ \\
\hline$I_{r m s .}$ & $\begin{array}{l}\text { root mean square value of current } \\
\text { (A) }\end{array}$ & $\phi_{X_{0}} \quad$ relative phase angle of $X_{0}\left(^{\circ}\right)$ \\
\hline$m_{1}$ & peak mass flow rate oscillating at the & relative phase angle of $P_{1}\left({ }^{\circ}\right)$ \\
\hline & boundary between the compression & relative phase angle of $P_{2}\left({ }^{\circ}\right)$ \\
\hline$m_{2}$ & $\begin{array}{l}\text { volume and the aftercooler }\left(\mathrm{kg} \mathrm{s}^{-1}\right) \\
\text { peak mass flow rate oscillating at the }\end{array}$ & relative phase angle of $P_{b}\left({ }^{\circ}\right)$ \\
\hline & boundary between the regenerator & relative phase angle of $m_{1}\left(^{\circ}\right)$ \\
\hline$m_{p}$ & $\begin{array}{l}\text { and the cold-end }\left(\mathrm{kg} \mathrm{s}^{-1}\right) \\
\text { piston mass }(\mathrm{kg})\end{array}$ & relative phase angle of $m_{2}\left(^{\circ}\right)$ \\
\hline$P_{1}$ & $\begin{array}{l}\text { dynamic pressure magnitude at the } \\
\text { compression volume }(\mathrm{Pa})\end{array}$ & \\
\hline$P_{2}$ & $\begin{array}{l}\text { dynamic pressure magnitude at the } \\
\text { cold expansion volume }(\mathrm{Pa})\end{array}$ & \\
\hline$P_{b}$ & $\begin{array}{l}\text { dynamic pressure magnitude at the } \\
\text { bouncing volume }(\mathrm{Pa})\end{array}$ & \\
\hline$Q_{\text {cond. }}$ & conductive loss $(\mathrm{W})$ & \\
\hline$Q_{\text {cond.mat. }}$ & conductive loss through matrix $(\mathrm{W})$ & \\
\hline$Q_{e d d y}$ & eddy current loss $(\mathrm{W})$ & \\
\hline$Q_{\text {fric. }}$ & friction loss acting on the piston (W) & \\
\hline$Q_{\text {ineff. }}$ & ineffectiveness loss (W) & \\
\hline$Q_{\text {pre. }}$ & pressurization loss (W) & \\
\hline$Q_{\text {rad. }}$ & radiative loss $(\mathrm{W})$ & \\
\hline$Q_{\text {shuttle }}$ & shuttle loss (W) & \\
\hline$V$ & voltage $(\mathrm{V})$ & \\
\hline$V_{0}$ & peak voltage $(\mathrm{V})$ & \\
\hline$W_{\text {in }}$ & electric input $(\mathrm{W})$ & \\
\hline$W_{P d V 1}$ & $\begin{array}{l}\text { mechanical work at the compression } \\
\text { volume (W) }\end{array}$ & \\
\hline$W_{P d V 2}$ & $\begin{array}{l}\text { mechanical work (or gross } \\
\text { refrigeration) at the cold expansion } \\
\text { volume }(\mathrm{W})\end{array}$ & \\
\hline$X_{0}$ & $\begin{array}{l}\text { piston stroke magnitude from its } \\
\text { neutral position }(\mathrm{m})\end{array}$ & \\
\hline
\end{tabular}




\section{Introduction}

A Stirling-type pulse tube refrigerator (PTR) has many advantages over other types of cryocoolers in that it has no moving parts at the cold expansion volume, simple geometry, less mechanical vibration and electromotive force (EMF) noise. A cryocooler accompanied with an oil-free linear compressor is completely free from a clogging problem so that it possesses high mechanical work conversion efficiency with no valve loss and promises long operation life. Especially, due to its high operational frequency, it is possible for the system to accept a 'higher power' per specific volume and thus this implies that the whole system becomes compact (Wang, Dai et al. 2008). Due to the aforementioned advantages, it is increasingly employed in the areas such as High Temperature Superconductor (HTS) application, basic scientific research, infrared detector systems for military and space missions (Radebaugh 2000, Ross and Boyle 2006).

\section{A. Basic operational principle of Stirling-type PTR}

Fig. 1 represents a schematic of PTR. It is mainly constituted of a compressor, a regenerator, a pulse tube, heat exchangers and a phase controller. As the piston of the compressor oscillates, the working gas (helium) also moves periodically back and forth while the pressure of the PTR increases and decreases. The working gas flows from the compressor to the regenerator at $T_{a}$ (aftercooler temperature) and leaves the regenerator to the pulse tube around $T_{c}$ (cold-end temperature). In other words, thermal energy is temporarily exchanged between the regenerator matrix and the working gas when it flows back and forth through the regenerator. In the regenerator and heat exchangers, the temperature temporal fluctuation can be negligible because the heat exchange area is very large. Since, however, in the pulse tube, the gas is thermally isolated (adiabatic condition), the working gas temperature instantaneously changes with the 
pressure oscillation. As depicted in the graph in Fig. 1, we can imagine a gas element near the pulse tube warm-end where the gas packet moves to the pulse tube when the pressure of the pulse tube is relatively low. At this moment, the gas cools down and its temperature becomes identical to $T_{w}$ (warm-end temperature). Later in the cycle, when the same amount of gas is displaced from the pulse tube toward the warm-end heat exchanger (WHX), the gas temperature becomes higher than $T_{w}$ due to pressurization. At the same time, the WHX absorbs heat from the gas and rejects to outside. Consequently, it cools down the gas to the temperature of $T_{w}$. At the pulse tube cold side, there is an opposite effect: the working gas flows in the pulse tube via the cold-end heat exchanger (CHX) when the pressure is increased with the temperature of $T_{c}$ and the working gas flows back when the pressure becomes low with the temperature below $T_{c}$ (adiabatic expansion process): these periodical flow and pressure change create the desired refrigeration effect at the CHX.

\section{B. Literature reviews on Stirling-type PTR below $20 \mathrm{~K}$}

Typically, multi-stage configuration of Stirling-type PTR has been adopted to obtain temperature below 20 K (Chan, Nguyen et al. 2003, Foster, Olson et al. 2003, Nast, Olson et al. 2003, Nguyen, Yeckley et al. 2004, Poncet, Charles et al. 2005, Yang and Thummes 2005, Yan, Chen et al. 2009, Dietrich and Thummes 2010). Along with the development of the multi-stage configuration, several researchers have attempted to achieve lower temperature with a 'singlestage configuration'. Single-stage configuration is attractive due to its inherent simplicity. Compared to multi-stage configurations, it is much simpler in that only one phase controller and one compressor are required. At present, however, a single-stage PTR can only provide a cooling capacity of under $0.5 \mathrm{~W}$-level at $35 \mathrm{~K}$ cooling temperature with the input power less than $250 \mathrm{~W}$ 
(Yang, Hou et al. 2008, Yang, Xun et al. 2010, Dang 2012). Specifications of the Stilring-type PTRs mentioned above are summarized in Table 1.

\section{Proposed concept and objectives}

As focused in the literature reviews, mass flow is always produced by a compressor situated at room-temperature. An alternative approach that we propose in this paper, is to generate the mass flow directly by a cold compressor placed at a 'cold temperature', where 'cold' means lower temperature than $120 \mathrm{~K}$ which is never achieved naturally on earth. The mass flow generated by the cold compressor is precooled by traveling through a regenerator and finally produces an expansion PV work near the cooling target temperature. The cyclic integration of the mass flow and the pressure results in work and is called a pressure-volume work, PV work. near the cooling target temperature. At this situation, since the temperature difference between the warm-end where the compression occurs and the cold-end where the working gas expands becomes small, the working gas will experience less temperature variation during the regenerative process. This fact signifies that the pressure and the mass flow transmitted to the cold-end are efficiently convertible to a cooling effect with low-level input power to the cold compressor. Characteristics of this concept are listed as follows.

(i) Extension of operating temperature range from 'cold state' to 'colder state'

(ii) Generation of mass flow at 'cold state'

(iii) Transmission of the mass flow from 'cold state' to 'colder state' without involving a precooling process

(iv) Reduction of input power consumed in the precooling process 
In National Aeronautics and Space Administration (NASA), a miniature PTR which is similar to this concept has been prepared and tested with a linear compressor that operates around $150 \mathrm{~K}$ for future space mission (Nast, Helvensteijn et al. 2014). It is understandable that utilizing a cryogenic reservoir and regulating the operating temperature range of the PTR should enable a PTR to operate for diverse space applications, e.g. space satellite, inside of lunar crater, etc. We can also devise a cascade refrigeration system which is conjugated with other types of refrigeration systems. These are technically well-developed and widely-spread gas liquefaction industries that provide liquefied natural gas (LNG), liquid nitrogen $\left(\mathrm{LN}_{2}\right)$, liquid oxygen (LOX), etc. As conceptually illustrated in Fig. 2, by utilizing a 'cold reservoir' as the virtual precooling stage, the PTR can extend its operating temperature to the region which cannot be easily reached by a single stage refrigerator. Being relied on the existing infra-structure of gas liquefaction industry, this concept can be implemented for liquefying much lower temperature cryogenic fluids such as liquid helium ( $\mathrm{LHe})$ or liquid hydrogen $\left(\mathrm{LH}_{2}\right)$.

In this research paper, a Stirling-type PTR equipped with a cold linear compressor is to be specifically developed and tested. The cryogenically operating linear compressor produces mass flow around $80 \mathrm{~K}$ and this mass flow is transmitted to the cold expansion volume through the multi-layered regenerator. At the cold-end side, it generates cooling effect to reach the target temperature of $20 \mathrm{~K}$. This paper mainly focuses; (1) on understanding the mechanical characteristics of the PTR system operating near its resonant frequency by comparing the experimental data with the numerical model (SAGE) and (2) on identifying the major thermal loss that originates in the multi-layered regenerator with a sophisticated regenerator model (REGEN). 


\section{Experimental apparatus}

The PTR described in this paper, is designed for operating at below $80 \mathrm{~K}$ with the target cold-end temperature of $20 \mathrm{~K}$ with non-zero cooling power. As illustrated in Fig. 3, a cold linear compressor, an aftercooler, a warm-end heat exchanger (WHX) and a phase controller are designed to be operated near $80 \mathrm{~K}$. The cold linear compressor, especially, needs to operate under cryogenic environment without experiencing any failure by a thermal contraction problem. In order to minimize heat generation due to friction of the oscillating piston of the compressor, the friction-free configuration is very important. It also has to operate with high mechanical reliability at cryogenic temperature. The target temperature at the cold-end heat exchanger $(\mathrm{CHX})$ is set to be $20 \mathrm{~K}$. However, it is difficult for the regenerator to meet the cooling requirements at the cold-end of the PTR with a 'simple configuration'. This is mainly due to the lack of volumetric heat capacity of regenerative material (relative to that of the working gas at the 'low temperature section') and poor heat transfer phenomenon. The latter one is directly related to the thermal penetration depth of heat into the working gas and this problem becomes more significant not only at 'low temperature condition' but also under 'high frequency condition'. The main features of the regenerator, therefore, are distinctively listed below.

(i) Multi-layered structure (with two different materials)

(ii) Tiny regenerative material (small hydraulic diameter)

(iii) Operating under high frequency condition (near $50 \mathrm{~Hz}$ ) between $20 \mathrm{~K}$ and $80 \mathrm{~K}$ 


\section{A. Cold linear compressor}

The cold linear compressor adopts 'moving-magnet' and 'hermetic' configurations. The compressor consists of a reciprocating piston with a magnet array, a cylinder body, inner/outer yokes, an electric coil and a housing which is submerged into liquid nitrogen bath. The piston and the cylinder body are made of aluminum and both are coated with Teflon ${ }^{\circledR}$. Radiallymagnetized permanent magnet segments are bonded by means of cryogenically compatible epoxy (Stycast $\left.{ }^{\circledR} 2850 \mathrm{FT}\right)$ on the thin stainless steel frame connected with the moving piston. A gas bearing is implemented to maintain the radial-clearance gap between the piston and the cylinder body. Due to the upward orientation of the compression volume, a displacement limiter (stroke limit from neutral position to maximum of $6 \mathrm{~mm}$ ) is additionally installed to prevent the moving piston from being displaced out of the electro-magnetic force effective zone. Without using a flexure-system, the piston-cylinder assembly is secured for mechanical reliability. The thrust force of the linear compressor assembly is experimentally measured to be $4.8 \mathrm{~N} \mathrm{~A}^{-1}$ which indicates a slightly lower value (by approximately 5 10\%) than that of normal operation at room-temperature environment. A dynamic pressure transducer (601A, Kistler; sensitivity of 16 $\mathrm{pC}$ bar $^{-1}$ with temperature coefficient of below $10^{-4} \% \mathrm{~K}^{-1}$ (operational temperature range of 77 $\mathrm{K} 473 \mathrm{~K})$ ), is also positioned to measure the instantaneous pressure generated in the compression volume. An accelerometer (8730AE500M8, Kistler; sensitivity of $10 \mathrm{mV} \mathrm{g}^{-1}$ with temperature coefficient of below $0.05 \% \mathrm{~K}^{-1}$ (operational temperature range of $77 \mathrm{~K} 425 \mathrm{~K}$ )) is mounted on the piston assembly to measure its displacement. This set of sensors will be mainly used for calculating the effective mechanical work (PV work) fed to the warm side of the regenerator. All the components above are thermally anchored to a copper structure that is cooled by liquid nitrogen and also sealed with stainless steel housing. 


\section{B. Stirling-type PTR components}

The selection of the regenerative material is exceedingly important and always the first task to consider for designing a cryocooler. For efficient heat exchange in the regenerator, three conditions have to be satisfied (Radebaugh, Marquardt et al. 1999, Ackermann 2013);

(i) The volumetric heat capacity of the regenerative material is sufficiently high relative to that of the oscillating working gas (helium).

(ii) The characteristic length of the regenerative matrix should be smaller than that of the thermal penetration depth of heat into the matrix, so that the volumetric heat capacity of the regenerative material is fully used.

(iii) Hydraulic diameter of the matrix channels should be smaller than the thermal penetration depth of heat into the working gas (helium) to provide sufficient heat exchange with the fluid.

The thermal penetration depth of heat into the matrix or the working gas is defined as $\delta_{t}=\alpha^{1 / 2}(\pi f)^{-}$ 1/2. A combination of $75 \mu \mathrm{m}$-diameter antimonial lead spheres $\left(\mathrm{Pb}_{96} \mathrm{Sb}_{4}\right)$ and \#400 woven stainless steel mesh is selected after considering the above conditions at the operating target. The regenerator shell has the inner diameter of $21.6 \mathrm{~mm}$, the wall thickness of $0.3 \mathrm{~mm}$ and the total height of $40 \mathrm{~mm}$. The tiny lead spheres are juxtaposed as the length of $10 \mathrm{~mm}$ at the location closest to the cold-end. The porosities of the mesh screens and the lead spheres are measured to be 0.65 and 0.35 , respectively. E-type thermocouples are soldered at the outer surface of the regenerator (TC1 TC5, $5 \mathrm{~mm}$-equal spacing) for observing the temperature distribution along its axial direction, and their junctions are thermally anchored at liquid nitrogen for high 
measurement accuracy. The pulse tube has the inner diameter of $12.1 \mathrm{~mm}$, the wall thickness of $0.3 \mathrm{~mm}$ and $75 \mathrm{~mm}$ high. As tabulated in Table 2, the heat exchangers (aftercooler, WHX and CHX) have several tapered (or straight) slit channels radially which are carved on copper with electric discharge machining (EDM) method and the channels are axisymmetric with respect to the flowing direction. All the slit-type heat exchangers are designed to have the temperature difference between the working gas and the fin surface not to exceed $1 \mathrm{~K}$ at the target heat lift. The tapered multiple-channel slit-type heat exchangers have the following advantages (Ki and Jeong 2012);

(i) Smooth flow connection between the converging and the diverging components of the PTR

(ii) No thermal contact resistance originated within the heat exchanger body

(iii) Geometrically axisymmetric structure with respect to the working gas flow

Several researchers have revealed three locations of the PTR that are likely the sources of significant flow mal-distribution; both ends of the pulse tube and the locus between the WHX and the phase controller entrance (this is mainly because of the presence of severe curved flow, thermo-hydraulic gradient, in the radial direction of the PTR components.) (Garaway, Taylor et al. 2009, Lewis, Taylor et al. 2010, Park, Ko et al. 2016). Although the multiple-channel heat exchanger has several advantages as mentioned above, the flow straighteners which consist of a few layers of \#200 woven copper mesh (total thickness of $3 \mathrm{~mm}$ ) are inserted at the connection parts in order to avoid the inherent flow mal-distribution problem (Ki and Jeong 2010). On the outer surface of the CHX and the WHX, resistance thermometers (Cernox ${ }^{\circledR}$ RTD, Lakeshore; 
measurement accuracy of $\pm 9 \mathrm{mK}$ at $20 \mathrm{~K}$ and $\pm 16 \mathrm{mK}$ at $80 \mathrm{~K}$ ) and a nichrome-wire heater are attached at the CHX to measure the refrigeration capacity at the corresponding temperature. The WHX is connected to the inlet of an inertance tube whose inner diameter and length are $3.6 \mathrm{~mm}$ and $1.6 \mathrm{~m}$, respectively, and with a reservoir of $500 \mathrm{cc}$ volume, in series. A dynamic pressure sensor (601A, Kistler), is also installed to monitor the pressure at the inlet of the inertance tube and this pressure amplitude is almost same with the pressure amplitude at the cold-end (due to the compliance effect of the pulse tube, their phases are not same.).

The completed PTR system is shown in Fig. 4 and its geometrical specifications are tabulated in Table 3. All the cold parts are thermally insulated at high vacuum (below $10^{-5}$ Torr) with a copper radiation shield cooled by liquid nitrogen. The WHX, furthermore, is thermally linked to the surface of the copper radiation shield by means of copper braid wires with thin indium sheets as an interfacial material. A dynamic absorber is implemented to maintain the mechanical stability of the PTR system. It is mainly composed of a spring and a balancing mass. The latter one is directly calibrated with the operating frequency. 


\section{Experiments}

The experimental procedure is explained in the flowchart of Fig. 5. Table 3 lists general operating parameters of the Stirling-type PTR system. All the instantaneous data (instantaneous pressures and displacement) are conditioned with charge amplifiers (5015A and 5127B, Kistler) and these are recorded by an NI data acquisition (DAQ) board (SCXI-1600 and SCXI-1125, National instrument) at sampling rate of $5 \mathrm{kHz}$ without any filter. The cool-down history of the Stirling-type PTR system is recorded as shown in Fig. 6(a). Fig. 6(b) shows the temperature distribution at the steady-state with the operating frequency of $50 \mathrm{~Hz}$. In this case, a no-load temperature of $18.7 \mathrm{~K}$ was achieved and it took 10 minutes from $80 \mathrm{~K}$. The temperature difference between CHX and TC5 seems too large. This fact manifests the reason why the cooling performance of the Stirling-type PTR is limited and it will be discussed in the next chapter. Fig. 7 shows the no-load temperature variation with the operating frequency. The typical resonant characteristics of PTR is well observed in this figure. 


\section{Experimental and numerical validations on dynamic characteristics}

Thermo-acoustic software (SAGE) was used to simulate the operational characteristics of the developed PTR system (Gedeon 2016). This model calculates the piston stroke, the pressure, the mass flow rate and the corresponding phase angles with respect to the input current fed to the linear compressor. The piston stroke and its phase angle relative to that of the input current are calculated and these are compared with the experimental data, as shown in Fig. 8(a). As mentioned before, for all the frequency domain, the piston strokes do not exceed its allowable value of $6 \mathrm{~mm}$. Typically, at the resonance frequency of the piston, the piston movement and the input current oscillate with $90^{\circ}$ phase (out-phase) angle between them, $\phi_{X 0}$ as labeled in Fig. 8(b). Actually, the mechanical damping $\left(c_{m}\right)$ is small compared to that of gas damping $\left(c_{g}\right)$ and so the former one is neglected in computing the phase angles. Fig. 8(b) represents the force vectors acting on the moving piston without considering a mechanical spring force (flexure-free design) and a mechanical damping. This diagram has been obtained by substituting the variables of Eqs. 2 into Eq. 1 (neglecting the pressure variation at the bouncing volume; $P_{b}=0$ ) (Heun, Collins et al. 1997, Ko and Jeong 2008).

$$
\begin{aligned}
& m_{p} \ddot{x}+c_{m} \dot{x}+\not / m=-\left(P-P_{b o}\right) A_{p}+K_{E} I \\
& I=I_{0} \sin (\omega t) \\
& x=X_{0} \sin \left(\omega t+\phi_{X_{0}}\right) \\
& P=P_{1} \sin \left(\omega t+\phi_{P_{1}}\right) \\
& P_{b o}=P_{b} \sin \left(\omega t+\phi_{P_{b}}\right)
\end{aligned}
$$


As shown in Fig. 7, the lowest CHX temperature was recorded at the frequency of $50 \mathrm{~Hz}$ and the compressor also operates near its resonance state (The phase angle, $\phi_{X 0}$, is in the range of $100^{\circ} \sim 130^{\circ}$ when the operating frequency is between $47 \mathrm{~Hz}$ and $54 \mathrm{~Hz}$, as depicted in Fig. 8(a)). The most important phase angle in judging whether the moving piston generates the mechanical work effectively or not, is the angle between the pressure at the compression volume and the piston movement. Fig. 9(a) shows the frequency dependency of the dynamic pressure amplitudes at the compression volume and the cold expansion volume. The relative phase angles are also calculated and compared with the experimental data, as shown in Fig. 9(b). It is found that all the measured physical variables agree well with the results of the numerical analysis. From the experimental data of Figs. 8 and 9, we can evaluate the mechanical work rate at the compression volume by using the following equation.

$$
\dot{W}_{P d V 1}=f \int_{\tau} P_{1} d V=\pi f\left|P_{1}\right|\left|X_{0}\right| A_{p} \sin \left(\phi_{X_{0}}-\phi_{P_{1}}\right)
$$

At the compression volume, the mechanical work is calculated and compared with the numerical results, as shown in Fig. 10(a). The experimental data shows that the measured mechanical work slightly exceeds the numerical prediction. For further investigation on this phenomenon, the obtained data are processed with the force phasor diagram (illustrated in Fig. 8(b)) by using the law of cosine. Table 4 shows the comparison between the experimentally measured phase angle and those calculated by a phasor diagram with the experimentally measured magnitudes of all the physical variables. Results indicate that there exist additional forces acting on the moving piston that we do not consider on the phasor diagram. This might be due to the phase discrepancies between the real and the ideal situations (mainly due to the presence of back pressure fluctuation 
at the bouncing volume). Therefore, the force phasor diagram can be modified as shown in Fig. 8(c) (from the dotted lines to the solid lines, where the dotted lines are inferred for describing that depicted in Fig. 8(b).) and this can readily explain that the phase angle between the piston stroke and the pressure at the compression volume is shifted to a larger value than the phase angle expected by the numerical computation. Next, in order to quantify the losses generated in the cold linear compressor, the voltage and the current across the electric coil are measured in real time and the actual electric power $\left(W_{i n}\right)$ is calculated by Eq. 4.

$$
\dot{W}_{i n}=f \int_{\tau}(V \cdot I) d t=\frac{1}{2} V_{0} I_{0} \cos \phi_{v}
$$

A linear motor consumes power primarily in three ways; (1) by doing useful mechanical work on the applied load; (2) by generating ohmic loss in the drive coil; (3) by causing eddy current loss in the iron yokes and (4) by doing work to overcome various frictional forces impeding the applied load. Since the ohmic loss is generally the dominant loss term in a good linear motor, the linear motor efficiency can be expressed as Eq. 5(a) (Ross Jr, Johnson et al. 1994). In this paper, the compression efficiency is estimated by the ratio of the useful work to the electric input as Eq. $5(b)$.

$$
\begin{aligned}
& \eta_{\text {comp. }}=\frac{\dot{W}_{\text {in }}-I_{r m s .}{ }^{2} R_{c}}{\dot{W}_{\text {in }}} \\
& \eta_{\text {comp. }}=\frac{\dot{W}_{\text {in }}-I_{r m s .}{ }^{2} R_{c}-\left(\dot{Q}_{\text {eddy }}-\dot{Q}_{\text {fric. }}\right)}{\dot{W}_{\text {in }}}=\frac{\dot{W}_{P d V 1}}{\dot{W}_{\text {in }}}
\end{aligned}
$$


Fig. 10(b) presents the loss mechanisms within the linear compressor and these are compared with the numerical results. The experimental results indicate that approximately only $10 \%$ of the input power is dissipated by heat and the compression efficiency always exceeds $85 \%$ for all frequency domain as shown in Fig. 11. 


\section{Experimental and numerical validations on thermal characteristics}

\section{A. Numerical model descriptions}

If there is no thermal loss, the provided PV expansion power at the cold-end should be completely utilized for absorbing the heat from the environment (refrigeration effect). In the actual situation, however, there exist several thermal losses as follows (Ko and Jeong 2008, Babaelahi and Sayyaadi 2015).

(i) Regenerator loss, $Q_{\text {ineff: }}$ : the integration of the enthalpy (net enthalpy) at the cold-end of the regenerator over one cycle.

$$
Q_{\text {ineff. }}=\int_{\tau} \frac{\phi A \rho(L, t) v(L, t) h(P(L, t), T(L, t))}{\tau} d t
$$

where, $\phi$ is the porosity in the regenerator, $\mathrm{A}$ is the cross-sectional area of the regenerator $\left(\mathrm{m}^{2}\right), \rho$ is the gas density $\left(\mathrm{kg} \mathrm{m}^{-3}\right), v$ is the gas velocity $\left(\mathrm{m} \mathrm{s}^{-1}\right), h$ is the gas enthalpy $\left(\mathrm{J} \mathrm{kg}^{-1}\right), P$ is the pressure (Pa), $t$ is the time (s) and $L$ means the position at the cold-end of the regenerator.

(ii) Thermal conduction loss through regenerative matrix, $Q_{\text {cond.mat }}$

$$
Q_{\text {cond.mat. }}=k_{\text {eff }} A \frac{d T}{d x}
$$

where, $k_{\text {eff. }}$ is the effective thermal conductivity of the matrix and $x$ is the position.

(iii) Shuttle loss at the pulse tube, $Q_{\text {shuttle }}$ : the thermal loss by touching periodically cold and warm parts of the pulse tube wall when the gas displacer moves back and forth within the wall of the pulse tube. (Jung and Jeong 2003)

(iv) Conductive thermal loss, $Q_{\text {cond }}$ 


$$
Q_{\text {cond.mat. }}=k A \frac{d T}{d x}
$$

where, $k$ is the thermal conductivity.

In principle, the gross potential refrigeration power can be calculated by Eq. 7(a) and the net refrigeration can be readily evaluated as the gross refrigeration power minus the thermal losses, as represented in Eq. 7(b).

$$
\begin{aligned}
& \dot{W}_{P d V 2}=f \int_{\tau} P_{2} d V=\frac{1}{2} \frac{\left|P_{2}\right|}{\rho}\left|\dot{m}_{2}\right| \cos \left(\phi_{P_{2}}-\phi_{\dot{m}_{2}}\right) \\
& \dot{Q}_{\text {net }}=\dot{W}_{P d V 2}-\dot{Q}_{\text {losses }}=\dot{W}_{P_{d V 2}}-\left(\dot{Q}_{\text {cond.mat }}+\dot{Q}_{\text {ineff. }}\right)_{\text {regen. }}-\left(\dot{Q}_{\text {shuttle }}+\dot{Q}_{\text {cond }}\right)
\end{aligned}
$$

To understand the complex losses more precisely for the high frequency $20 \mathrm{~K}$ regenerator, REGEN is used. An open source code, REGEN, is a sophisticated regenerator model developed by National Institute of Standards and Technology (NIST).

\section{B. Discussions}

Fig. 12(a) depicts the net refrigeration power (cooling capacity) at the cold-end. The discrepancy between the experimental results and the numerical predictions may be originated from the secondary flow in the pulse tube and auxiliary radiative thermal losses (Shiraishi, Murakami et al. 2007). For the detailed analysis, we classify the major losses generated in the regenerator and the whole system. According to the loss analysis, as illustrated in Fig. 12(b), the ineffectiveness loss abates the largest portion of the available expansion work at the cold-end by approximately $60 \%$. This value seems to be higher than $40 \%$ that is usually reported in the previous works by Radebaugh (Radebaugh, Marquardt et al. 1999, Radebaugh 2010). The conduction loss through 
the regenerative matrix is equivalent to about $20 \%$ of the potential work. It seems that the thermal conduction loss through the regenerative matrix is still high even if the thermal contact resistance of regenerator matrix tries to reduce it. The effective thermal conductivity is estimated by using the experimental temperature distribution on the outer surface of the regenerator, so that the value is determined to be $20 \%$ of its solid (lead) value. The conduction degradation factor of $20 \%$, in this paper, is slightly larger than that measured by Kuriyama et al. (Kuriyama, Kuriyama et al. 1997) and Lewis et al (Lewis and Radebaugh 2002) which is approximately 10\%. This might be due to the differences in the operating temperature range and the geometrical factor such as the porosity and the particle size. The 'high conduction loss' can be also inferred from the mean temperature variation along the regenerator at the steady-state (Fig. 6(b)). The thermocouple, TC5 as labeled in Fig. 6(b), is placed at the inter-boundary of the two different regenerator matrices, i.e. stainless steel and lead. It indicates $45 \mathrm{~K}$, which evidences that the temperature difference between both ends of the lead segment is unusually large compared to the whole temperature range of the regenerator. The large temperature variation in the lead matrix also results in 'high ineffectiveness loss'. Consequently, we deduce that the thermal losses (conductive and ineffectiveness losses) on the lead segment is too high so that the total length of the regenerator as well as that of the lead segment should be extended for reducing the above thermal losses. 


\section{Conclusions}

In order to obtain a 'colder state', a 'cold compressor and colder expander' concept has been proposed in this research paper. We have also demonstrated the result of this unique concept by experimental investigations. The Stirling-type PTR system driven by a cold linear compressor operating between $20 \mathrm{~K}$ and $80 \mathrm{~K}$ is developed and tested. The main features of the cold linear compressor are listed as follows.

(i) The hermetic-type linear compressor can stably operate without experiencing any mechanical failure near its resonance frequency of $50 \mathrm{~Hz}$. The clearance gap between the moving piston and the cylinder is maintained by a gas-bearing without implementing any mechanical flexure system.

(ii) The mass flow is produced at cold environment around $80 \mathrm{~K}$ and the maximum pressure-volume work (PV work) is recorded to be approximately $55 \mathrm{~W}$.

(iii) The electrical to mechanical work conversion ratio $\left(=W_{P d V l} / W_{\text {in }}\right)$ is attained to exceed over $85 \%$ for all the frequency domain.

The key features and the operational issues regarding to the Stirling-type PTR system are listed as follows.

(i) The lowest temperature at the cold-end is recorded $18.7 \mathrm{~K}$ in 10 minutes at the resonance frequency of $50 \mathrm{~Hz}$. The nominal heat lift of $0.4 \mathrm{~W}$ is measured at the cold temperature of $20 \mathrm{~K}$. 
(ii) The dynamic characteristic of the Stirling-type PTR is investigated by using a simple-phasor diagram that considers the back-pressure variation at the bouncing volume of the linear compressor. It is also found that the numerical model is able to explain reasonably well the behavior of all the physical variables.

Through further loss analysis on the regenerator and the whole system, it is concluded that the thermal duty on the lead segment implemented as the part of the regenerator seems to be very high. This is the main reason why only $4 \%$ of the available expansion work is converted to the cooling effect. The overall analysis result signifies that the 'cold compressor and colder expander' concept is viable and useful in many applications such as gas liquefaction industry and cold space environment. 


\section{Acknowledgement}

This research is supported by a grant from Space Core Technology Development Program of National Research Foundation of Korea (NRF-2013-042033) funded by Ministry of Science, ICT \& Future planning (MSIP). We also wish to thank National Institute of Standards and Technology (NIST) Cryogenics Technologies Group for providing REGEN3.3 program.

\section{Reference}

Ackermann, R. A. (2013). Cryogenic regenerative heat exchangers, Springer Science \& Business Media.

Babaelahi, M. and H. Sayyaadi (2015). "Modified PSVL: A second order model for thermal simulation of Stirling engines based on convective-polytropic heat transfer of working spaces." Applied Thermal Engineering 85: 340-355.

Chan, C., T. Nguyen, C. Jaco, B. Tomlinson and T. Davis (2003). High capacity two-stage pulse tube cooler. Cryocoolers 12, Springer: 219-224.

Dang, H. (2012). "40K single-stage coaxial pulse tube cryocoolers." Cryogenics 52(4): 216-220. Dietrich, M. and G. Thummes (2010). "Two-stage high frequency pulse tube cooler for refrigeration at $25 \mathrm{~K} . "$ Cryogenics 50(4): 281-286.

Foster, W., J. Olson, P. Champagne, B. Evtimov, E. Will, A. Collaco, T. Nast, R. Clappier, A. Mitchell and D. Jungkman (2003). Development of a high capacity two-stage pulse tube cryocooler. Cryocoolers 12, Springer: 225-232.

Garaway, I., R. T. Taylor, M. A. Lewis, P. E. Bradley and R. Radebaugh (2009). Characterizing Flow and Temperature Instabilities within Pulse Tube Cryocoolers Using Infrared Imaging. Cryocoolers, ICC Press.

Gedeon, D. (2016). SAGE. Athens, OH, Gedeon Associates.

Heun, M. K., S. A. Collins, D. L. Johnson and R. G. Ross, Jr. (1997). Investigation of Gas Effects on Cryocooler Resonance Characteristics. Cryocoolers 9. R. G. Ross, Jr., Springer US: 421-430.

Jung, J. and S. Jeong (2003). Surface Heat Pumping Loss in a Pulse Tube Refrigerator. Cryocoolers 12. J. R.G. Ross, Springer US: 371-378.

$\mathrm{Ki}$, T. and S. Jeong (2010). "Optimal design of the pulse tube refrigerator with slit-type heat exchangers." Cryogenics 50(9): 608-614.

$\mathrm{Ki}$, T. and S. Jeong (2012). "Step-by-step design methodology for efficient Stirling-type pulse tube refrigerator." International Journal of Refrigeration 35(4): 1166-1175.

Ko, J. and S. Jeong (2008). "Analysis on the stirling-type pulse tube refrigerator in consideration of dynamics of linear compressor." Cryogenics 48(1-2): 68-76.

Kuriyama, T., F. Kuriyama, M. Lewis and R. Radebaugh (1997). Measurement of heat conduction through stacked screens. Cryocoolers 9, Springer: 459-464.

Lewis, M. and R. Radebaugh (2002). Measurement of heat conduction through metal spheres. Cryocoolers 11, Springer: 419-425. 
Lewis, M. A., R. P. Taylor, R. Radebaugh, I. Garaway, P. E. Bradley and N. Collaboration (2010). "Investigation of Flow Nonuniformities in a Large $50 \mathrm{~K}$ Pulse Tube Cryocooler." AIP Conference Proceedings 1218(1): 68-75.

Nast, T., J. Olson, B. Evtimov and V. Kotsubo (2003). Development of a two-stage pulse tube cryocooler for $35 \mathrm{~K}$ cooling. Cryocoolers 12, Springer: 213-218.

Nast, T. C., B. P. M. Helvensteijn, E. Roth, J. R. Olson, P. Champagne and J. R. Maddocks (2014). Cryocooler with Cold Compressor for Deep Space Applications. Cryocooler 18. S. D. Miller and J. R.G. Ross, ICC Press: 39-44.

Nguyen, C., A. Yeckley, A. Culler, M. Haberbusch and R. Radebaugh (2004). Hydrogen/Oxygen Propellant Densifier Using a Two- Stage Pulse Tube Cryocooler. ADVANCES IN CRYOGENIC ENGEINEERING: Transactions of the Cryogenic Engineering Conference-CEC, AIP Publishing.

Park, J., J. Ko, J. Cha and S. Jeong (2016). "Stirling-type pulse tube refrigerator (PTR) with cold compression: Cold compressor, colder expander." Cryogenics 74: 66-72.

Poncet, J. M., I. Charles, A. Gauthier and T. Trollier (2005). Low Temperature High Frequency Pulse Tube Cooler Using Precooling. Cryocoolers 13. R. Ross, Jr., Springer US: 149-155.

Radebaugh, R. (2000). "Development of the pulse tube refrigerator as an efficient and reliable cryocooler." Proc. institute of refrigeration, London.

Radebaugh, R. (2010). "Foundation of Cryocoolers Short Course." Cryogenic Society of America.

Radebaugh, R., E. Marquardt and P. E. Bradley (1999). "Development of a pulse tube refrigerator for millimeter array sensor cooling: Phase I." ALMA Memo 281: 1-26.

Ross Jr, R. G., D. L. Johnson, G. R. Mon and G. Smedley (1994). "Cryocooler resonance characterization." Cryogenics 34(5): 435-442.

Ross, R. G. and R. F. Boyle (2006). An overview of NASA space cryocooler programs-2006, Pasadena, CA: Jet Propulsion Laboratory, National Aeronautics and Space Administration.

Shiraishi, M., M. Murakami, A. Nakano and T. Iida (2007). Visualization of Secondary Flow in an Inclined Double-Inlet Pulse Tube Refrigerator. Cryocoolers. S. D. Miller and J. R. G. Ross, ICC Press. 14: 277-284.

Wang, X., W. Dai, J. Hu, E. Luo and Y. Zhou (2008). "Performance of a Stirling-Type Pulse Tube Cooler for High Efficiency Operation at $100 \mathrm{~Hz}$." Cryocoolers 16: 157-162.

Yan, P., G. Chen, J. Dong and W. Gao (2009). "15K two-stage Stirling-type pulse-tube cryocooler." Cryogenics 49(2): 103-106.

Yang, J., X. Hou, L. Yang, Y. Zhou and L. Zhang (2008). High Frequency Single-Stage MultiBypass Pulse Tube Cryocooler for $23.8 \mathrm{~K}$. ADVANCES IN CRYOGENIC ENGINEERING: Transactions of the Cryogenic Engineering Conference-CEC, Vol. 53, AIP Publishing.

Yang, L. and G. Thummes (2005). "High frequency two-stage pulse tube cryocooler with base temperature below 20K." Cryogenics 45(2): 155-159.

Yang, L., Y. Xun, G. Thummes and J. Liang (2010). "Single-stage high frequency coaxial pulse tube cryocooler with base temperature below 30K." Cryogenics 50(5): 342-346. 


\section{Appendix: Thermodynamic approach on thermal efficiency}

In a quantitative way, comparing Carnot Coefficient of Performance (COP) of the current system with other systems (or conventional refrigeration system) is actually difficult because the operational temperature of the current system is quite different. At this point, we have tried to compare them based on basic thermodynamic principles with several assumptions. Let's imagine two refrigeration cycles; upper stage ( $300 \mathrm{~K} \sim 80 \mathrm{~K}$ operating temperature) and lower stage (80 $\mathrm{K} \sim 20 \mathrm{~K}$ operating temperature). Carnot COPs of each refrigeration cycle can be expressed as follows. (The terms, $\mathrm{COP}_{1}$ and $\mathrm{COP}_{2}$, are expressed in Carnot COP.)

$$
\begin{gathered}
C O P_{1}=\frac{\frac{Q_{c, 1}}{W_{i n, 1}}}{\frac{T_{c, 1}}{T_{h, 1}-T_{c, 1}}}=\frac{\frac{Q_{h, 2}}{W_{i n, 1}}}{\frac{T_{c, 1}}{T_{h, 1}-T_{c, 1}}} \\
\operatorname{COP}_{2}=\frac{\frac{Q_{c, 2}}{W_{i n, 2}}}{\frac{T_{c, 2}}{T_{h, 2}-T_{c, 2}}}=\frac{\frac{Q_{c, 2}}{Q_{h, 2}-Q_{c, 2}}}{\frac{T_{c, 2}}{T_{h, 2}-T_{c, 2}}}
\end{gathered}
$$

where, $T_{h}$ is the warm-end temperature $(\mathrm{K}), T_{c}$ is the cold-end temperature $(\mathrm{K}), Q_{c}$ is the cooling power at $T_{c}(\mathrm{~W}), Q_{h}$ is heat rejection at $T_{h}(\mathrm{~W}), W_{i n}$ is the input work $(\mathrm{W})$, and the subscriptions 1 and 2 denote upper and lower stages, respectively. The specific work (input work per unit cooling power at $T_{c, 2}$ ) can be expressed in terms of two cycles' Carnot COPs, as follows. 


$$
\frac{W_{i n, 1}}{Q_{c, 2}}=\frac{1+\frac{T_{c, 2}}{T_{h, 2}-T_{c, 2}} C_{2}}{\frac{T_{h, 1}}{T_{h, 1}-T_{c, 1}} C O P_{1} \frac{T_{c, 2}}{T_{h, 2}-T_{c, 2}} C O P_{2}}
$$

For $\mathrm{COP}_{1}=0.2$ (values obtained from commercial Stirling coolers for $80 \mathrm{~K}$ ), we understand that the Carnot $\mathrm{COP}$ of the combined refrigeration cycles can exceed 5\% when $\mathrm{COP}_{2}$ is approximately $14 \%$. This 5\% combined Carnot COP is much higher than that of other Stirlingtype PTRs, as tabulated in Table 1 in the introduction chapter. The table implies that the attainment of such low temperature $(20 \mathrm{~K})$ is a difficult task. In a cascade manner of the proposed refrigeration cycles, the operating temperature ratio of the lower stage, $T_{h, 2} / T_{c, 2}$, is almost identical to that of the upper stage, $T_{h, l} / T_{c, l}$. We believe that improving thermal performance of the lower stage is effective for increasing the combined Carnot COP. Currently, we are also investigating on the performance optimization of the system (especially for the regenerator and the phase controller), and the optimized result indicates a higher Carnot COP than $14 \%$. 
Table 1 Summary of specifications of the PTRs in the literatures

\begin{tabular}{cccccccc}
\hline \hline Year & Researcher & Type & $\begin{array}{c}\text { No-load } \\
\text { temp. } \\
(\mathbf{K})\end{array}$ & $\begin{array}{c}\text { Electric } \\
\text { input } \\
(\mathbf{W})\end{array}$ & $\begin{array}{c}\text { Cooling } \\
\text { temp. } \\
(\mathbf{K})\end{array}$ & $\begin{array}{c}\text { Cooling power } \\
\text { at cooling } \\
\text { temp. }(\mathbf{W})\end{array}$ & $\begin{array}{c}\text { Carnot } \\
\text { COP } \\
(\boldsymbol{\%})\end{array}$ \\
\hline $\mathbf{2 0 0 3}$ & Nast et al. & 2-stage & $19.8 \mathrm{~K}$ & $57 \mathrm{~W}$ & $35 \mathrm{~K}$ & $0.5 \mathrm{~W}$ & 6.6 \\
\hline $\mathbf{2 0 0 5}$ & $\begin{array}{c}\text { Yang and } \\
\text { Thummes }\end{array}$ & 2-stage & $19.6 \mathrm{~K}$ & $200 \mathrm{~W}$ & $35 \mathrm{~K}$ & $0.41 \mathrm{~W}$ & 1.6 \\
\hline $\mathbf{2 0 0 3}$ & Chan et al. & 2-stage & $27.8 \mathrm{~K}$ & $605 \mathrm{~W}$ & $35 \mathrm{~K}$ & $2.32 \mathrm{~W}$ & 3.5 \\
\hline $\mathbf{2 0 1 0}$ & $\begin{array}{c}\text { Dietrich and } \\
\text { Thummes }\end{array}$ & 2-stage & $13.7 \mathrm{~K}$ & $4.6 \mathrm{~kW}$ & $25 \mathrm{~K}$ & $12.9 \mathrm{~W}$ & 3.1 \\
\hline $\mathbf{2 0 0 3}$ & Olson et al. & 3-stage & $6.0 \mathrm{~K}$ & $120 \mathrm{~W}$ & $10 \mathrm{~K}$ & $75 \mathrm{~mW}$ & 1.8 \\
\hline $\mathbf{2 0 0 4}$ & $\begin{array}{c}\text { Nguyen et } \\
\text { al. }\end{array}$ & 2-stage & $18.0 \mathrm{~K}$ & $600 \mathrm{~W}$ & $18.3 \mathrm{~K}$ & $1.4 \mathrm{~W}$ & 3.6 \\
\hline $\mathbf{2 0 0 9}$ & Yan et al. & 2-stage & $14.2 \mathrm{~K}$ & $400 \mathrm{~W}$ & $35 \mathrm{~K}$ & $1 \mathrm{~W}$ & 1.5 \\
\hline $\mathbf{2 0 0 5}$ & Poncet et al. & 2-stage & $30.3 \mathrm{~K}$ & $173 \mathrm{~W}$ & $33.2 \mathrm{~K}$ & $0.3 \mathrm{~W}$ & 1.4 \\
\hline $\mathbf{2 0 0 8}$ & Yang et al. & $\begin{array}{c}\text { single } \\
\text { stage }\end{array}$ & $23.8 \mathrm{~K}$ & $200 \mathrm{~W}$ & $30 \mathrm{~K}$ & $0.3 \mathrm{~W}$ & 1.4 \\
\hline $\mathbf{2 0 1 0}$ & Yang et al. & $\begin{array}{c}\text { single } \\
\text { stage }\end{array}$ & $26.1 \mathrm{~K}$ & $200 \mathrm{~W}$ & $30 \mathrm{~K}$ & $0.21 \mathrm{~W}$ & 0.9 \\
\hline $\mathbf{2 0 1 2}$ & Dang & $\begin{array}{c}\text { single } \\
\text { stage }\end{array}$ & $29.7 \mathrm{~K}$ & $200 \mathrm{~W}$ & $40 \mathrm{~K}$ & $0.86 \mathrm{~W}$ & 2.8 \\
\hline
\end{tabular}


Table 2 Geometrical specifications of the slit-type heat exchangers

\begin{tabular}{ccccccc}
\hline \hline & $\begin{array}{c}\text { Inlet height } \\
(\mathbf{m m})\end{array}$ & $\begin{array}{c}\text { Outlet height } \\
(\mathbf{m m})\end{array}$ & $\begin{array}{c}\text { Width } \\
(\mathbf{m m})\end{array}$ & $\begin{array}{c}\text { Number } \\
\text { of slits }\end{array}$ & $\begin{array}{c}\text { Length } \\
(\mathbf{m m})\end{array}$ & $\begin{array}{c}\text { Heat lift } \\
(\mathbf{W})\end{array}$ \\
\hline Aftercooler & 11.1 & 8.9 & 0.3 & 40 & 80 & 100 \\
\hline WHX & 4.6 & 4.6 & 0.3 & 30 & 17 & 10 \\
\hline CHX & 9.2 & 4.6 & 0.3 & 30 & 17 & - \\
\hline
\end{tabular}

Table 3 Specifications of the Stirling-type PTR system and operating parameters

\begin{tabular}{|c|c|c|}
\hline $\begin{array}{c}\text { Linear } \\
\text { compressor }\end{array}$ & $\begin{array}{l}\text { Piston mass, } m_{p} \\
\text { Motor constant, } K_{E} \\
\text { Electric resistance, } R_{c} \\
\text { Electric inductance, } L_{c}\end{array}$ & $\begin{array}{l}260 \mathrm{~g} \\
4.8 \mathrm{~N} \mathrm{~A}^{-1} \\
0.05 \Omega \\
1.9 \mathrm{mH}\end{array}$ \\
\hline \multirow{5}{*}{$\begin{array}{l}\text { Pulse tube } \\
\text { refrigerator }\end{array}$} & Compression volume & $16,430 \mathrm{~mm}^{3}$ \\
\hline & Regenerator & $\begin{array}{c}21.6 \mathrm{~mm} \text { (I.D.), } 0.3 \mathrm{~mm}(\mathrm{~T}), 40 \mathrm{~mm}(\mathrm{~L}) \\
30 \mathrm{~mm} \text { portion (high temperature section); } \\
\# 400 \text { stainless steel mesh with porosity of } 0.65 \\
10 \text { mm portion (low temperature section); } \\
75 \text { um-diameter lead sphere with porosity of } 0.35\end{array}$ \\
\hline & Pulse tube & $12.1 \mathrm{~mm}$ (I.D.), $0.3 \mathrm{~mm}$ (T), $75 \mathrm{~mm}$ (L) \\
\hline & Heat exchangers & $\begin{array}{l}\text { Aftercooler: } 9,600 \mathrm{~mm}^{3} \text {; WHX: } 1,570 \mathrm{~mm}^{3} ; \mathrm{CHX} \text { : } \\
1,310 \mathrm{~mm}^{3} \\
\text { refer Table } 2 \text { and including flow straightener's volume }\end{array}$ \\
\hline & Phase controller & $\begin{array}{l}\text { Inertance tube: } 3.6 \mathrm{~mm} \text { (I.D), } 1.6 \mathrm{~m} \text { (L); Reservoir: } \\
500,000 \mathrm{~mm}^{3}\end{array}$ \\
\hline \multirow{3}{*}{$\begin{array}{c}\text { Operating } \\
\text { parameters }\end{array}$} & Operating temperature & Aftercooler: $80 \mathrm{~K}$; WHX: $90 \mathrm{~K}$; CHX: $20 \mathrm{~K}$ \\
\hline & Charging pressure & $2 \mathrm{MPa}$ \\
\hline & Input current & $9.7 \mathrm{~A}_{\mathrm{rms}}$ \\
\hline
\end{tabular}


Table 4 Comparison between the experimentally measured phase angle and the analytically estimated phase angle by force phasor analysis

\begin{tabular}{|c|c|c|c|c|c|c|c|c|}
\hline \multirow[t]{2}{*}{$\underset{(\mathbf{H z})}{f}$} & \multirow[t]{2}{*}{$\begin{array}{c}X_{0} \\
(\mathbf{m m})\end{array}$} & \multirow[t]{2}{*}{$\begin{array}{c}P_{1} \\
(\mathbf{k P a})\end{array}$} & \multicolumn{2}{|c|}{ Measured data } & \multicolumn{2}{|c|}{$\begin{array}{c}\text { Analytically } \\
\text { predicted from } \\
\text { measured data with } \\
\text { phasor diagram } \\
(\text { Fig. } 8(b))\end{array}$} & \multicolumn{2}{|c|}{$\begin{array}{c}\text { Deviation between } \\
\text { measured and } \\
\text { analytical data } \\
(\%)\end{array}$} \\
\hline & & & $\phi_{X 0}\left({ }^{\circ}\right)$ & $\phi_{P 1-X 0}\left(^{\circ}\right)$ & $\phi_{X 0}\left({ }^{\circ}\right)$ & $\phi_{P 1-X 0}\left(^{\circ}\right)$ & $\phi_{X 0}$ & $\phi_{P 1-X 0}$ \\
\hline 47 & 4.6 & 207.3 & 98.2 & 37.0 & 94.0 & 31.8 & 4.3 & 14.1 \\
\hline 48 & 4.8 & 214.7 & 102.0 & 35.2 & 97.9 & 30.7 & 1.0 & 12.8 \\
\hline 49 & 5.1 & 219.5 & 106.5 & 33.6 & 103.9 & 29.1 & 2.4 & 13.4 \\
\hline 50 & 5.3 & 224.8 & 110.9 & 31.5 & 109.0 & 27.8 & 1.7 & 11.7 \\
\hline 51 & 5.3 & 223.7 & 117.0 & 29.9 & 115.7 & 26.1 & 1.1 & 12.7 \\
\hline 52 & 5.4 & 222.1 & 122.8 & 27.7 & 123.1 & 24.4 & -0.2 & 11.9 \\
\hline 53 & 5.4 & 215.1 & 129.9 & 25.9 & 132.6 & 22.0 & -2.1 & 15.1 \\
\hline 54 & 5.3 & 205.3 & 136.3 & 24.1 & 140.7 & 19.7 & -3.2 & 18.3 \\
\hline
\end{tabular}




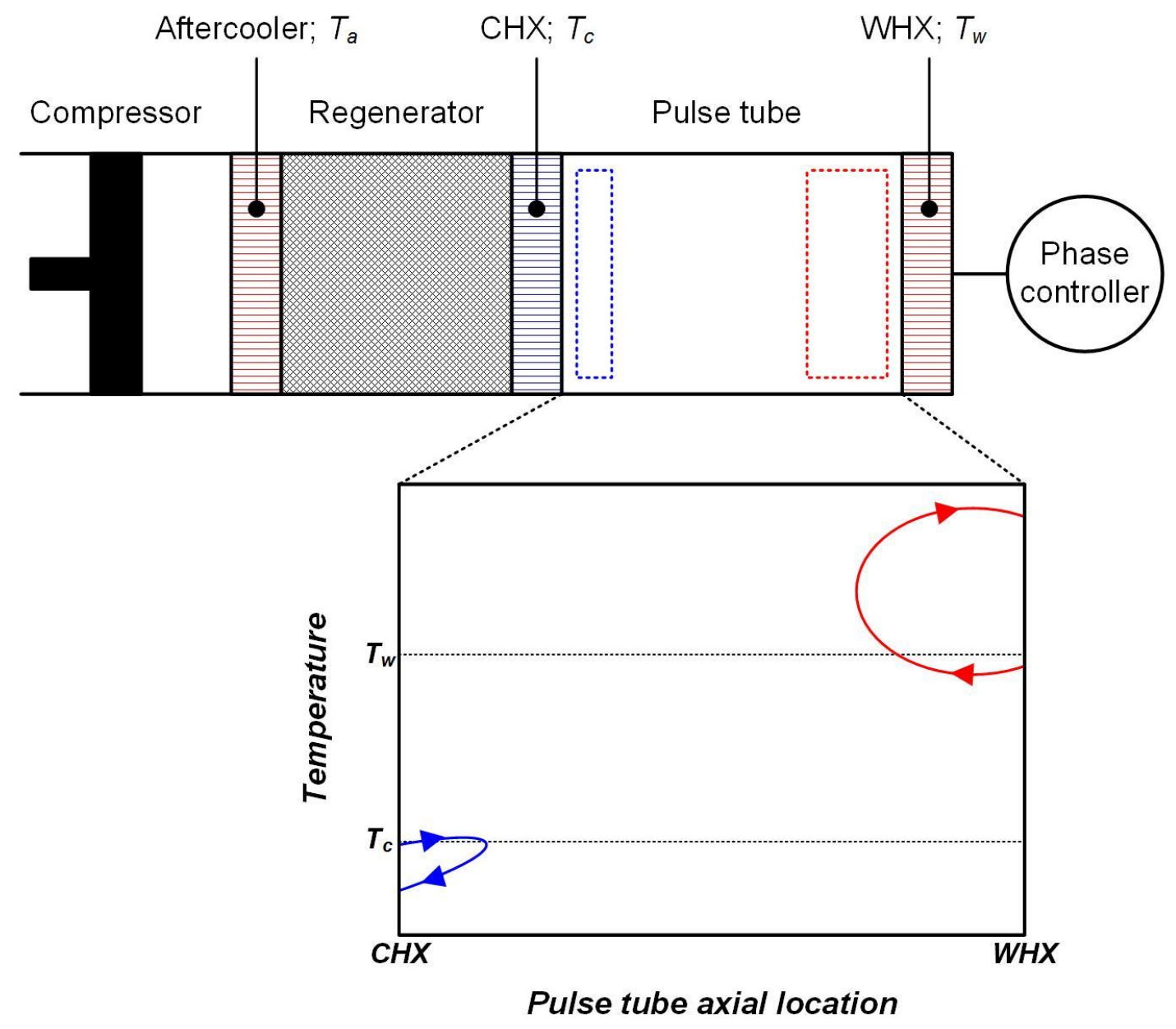

Fig. 1 Schematics of a typical PTR and temperature oscillation of gas packets (around CHX and WHX) in a pulsating tube 


\section{Equivalent}

refrigeration system

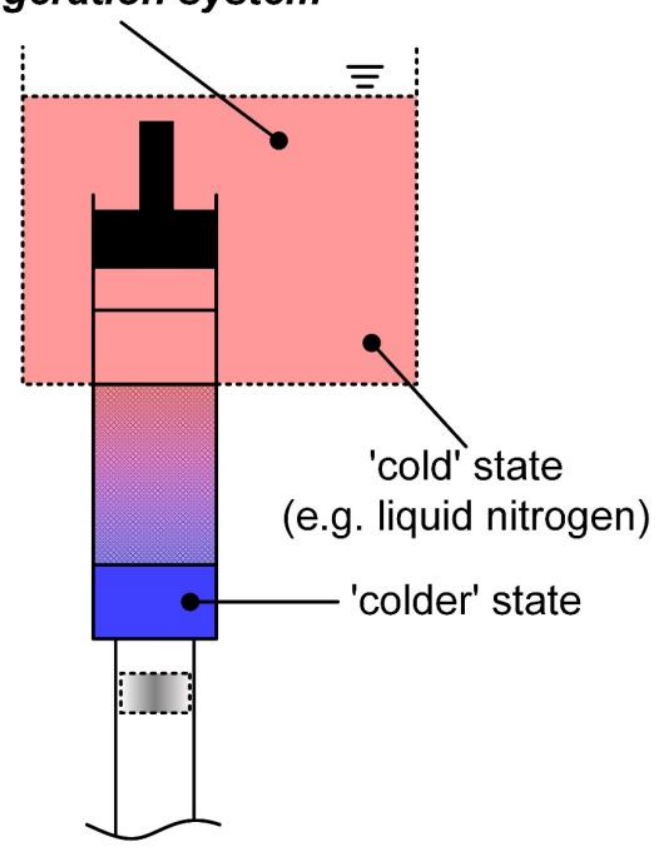

Fig. 2 Conceptual diagram for cascade-like refrigeration system of PTR conjugated with other refrigeration system 


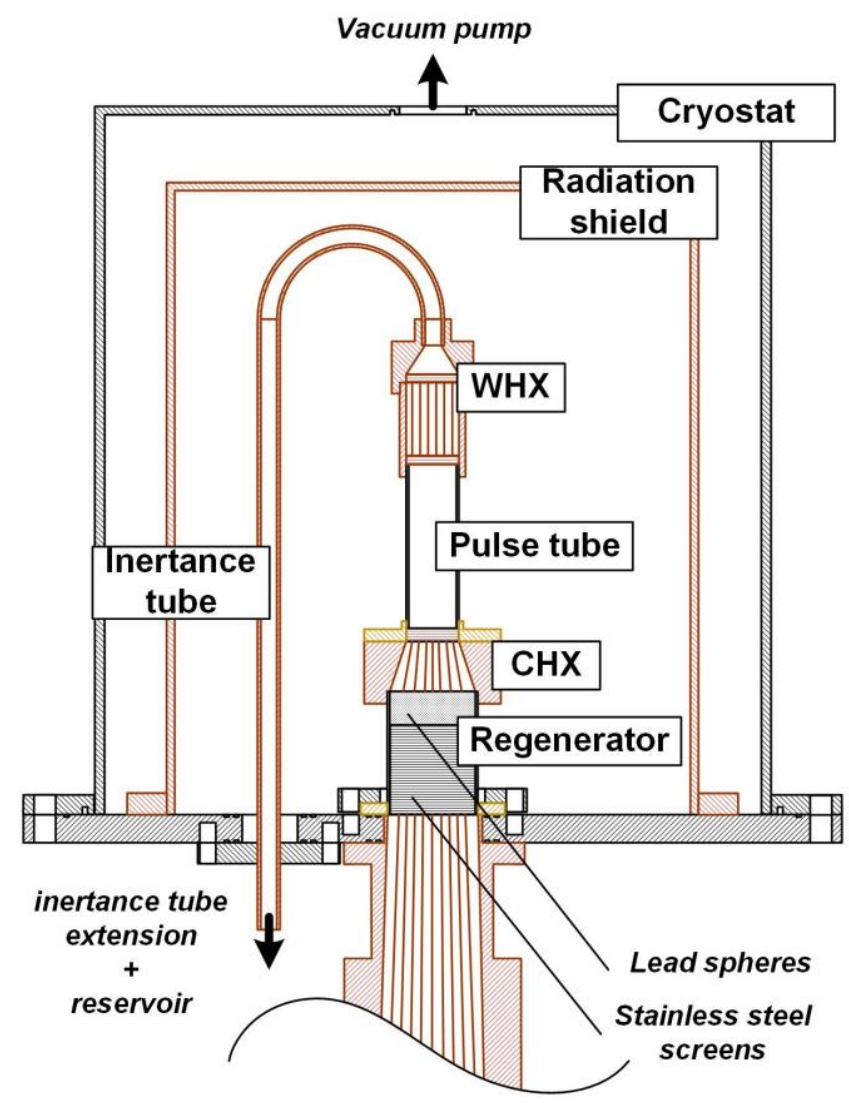

(a)

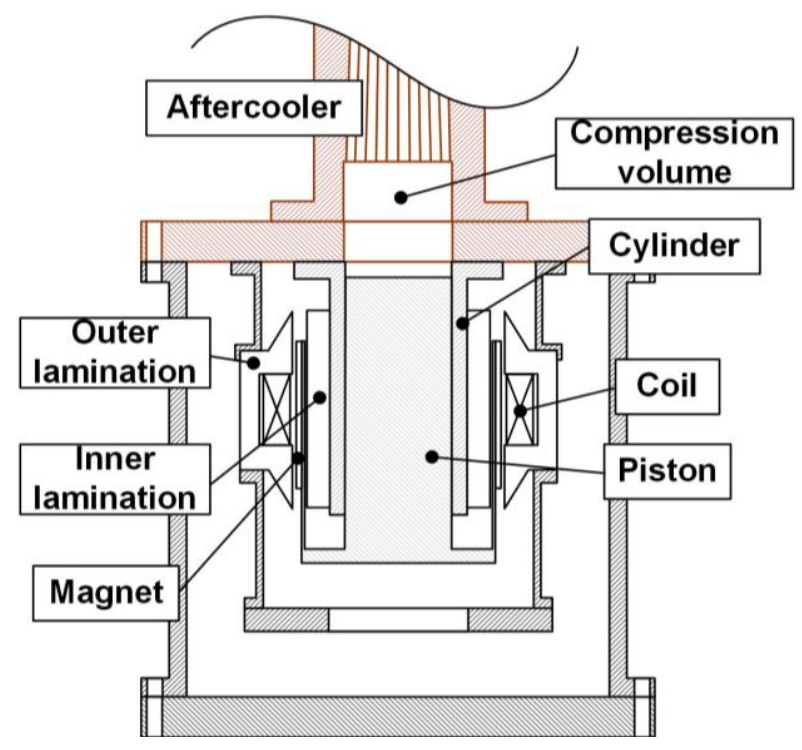

(b) 
Fig. 3 Schematic of the Stirling-type PTR system; (a) PTR components and (b) cold linear compressor 


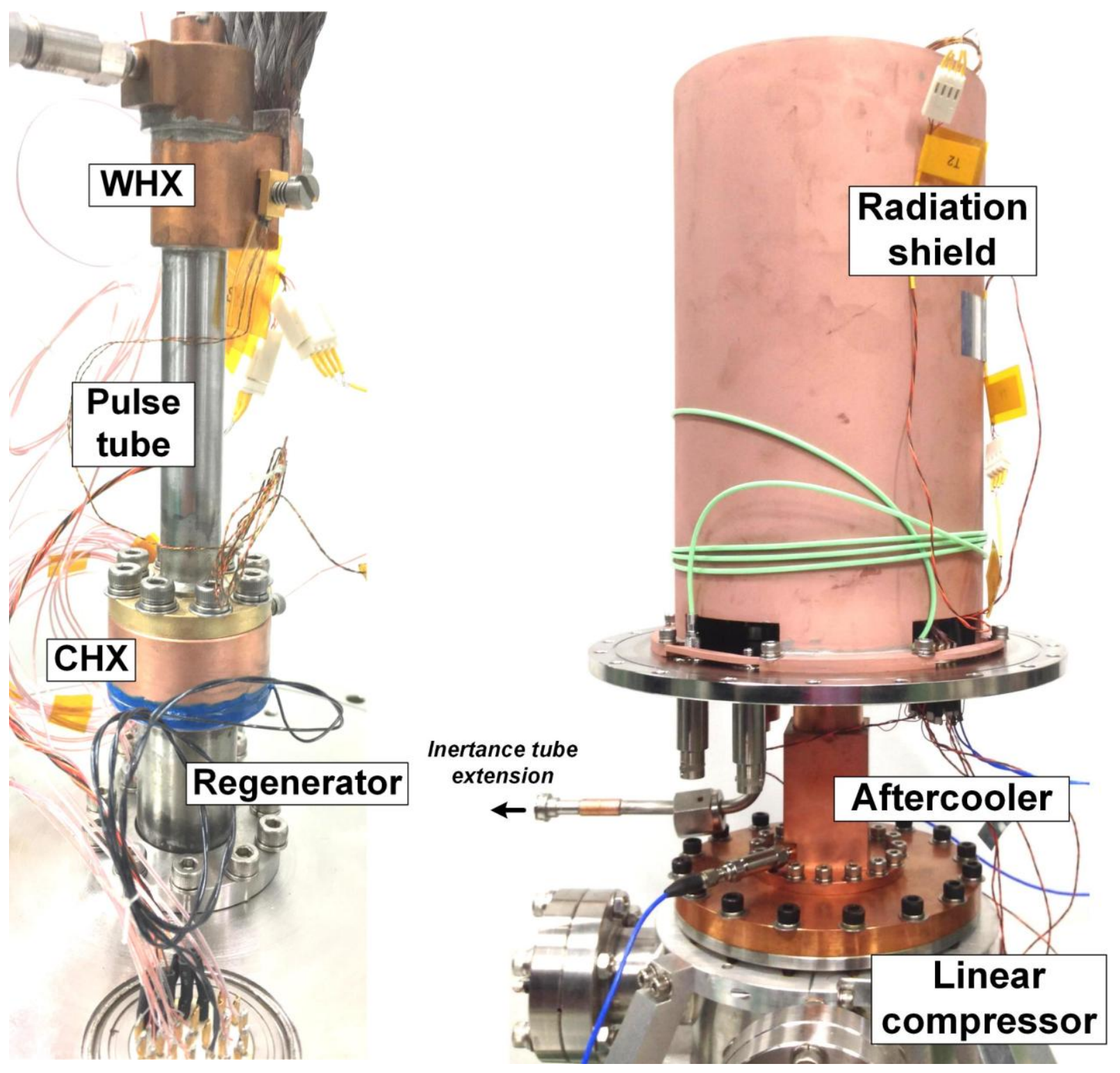

Fig. 4 Photos of completed Stirling-type PTR system without (left) with (right) thermal shield assembly 


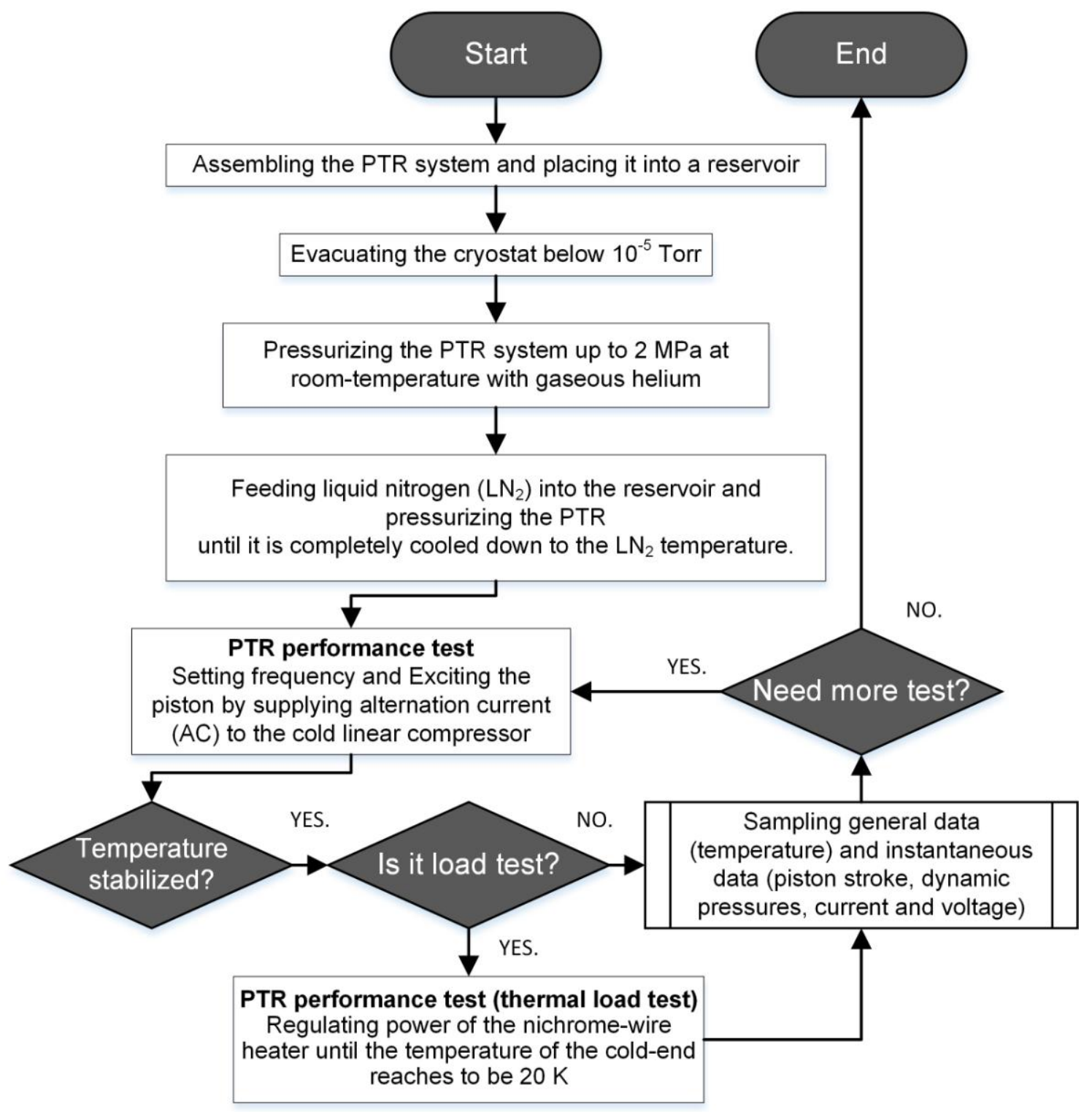

Fig. 5 Flowchart of experimental procedure 


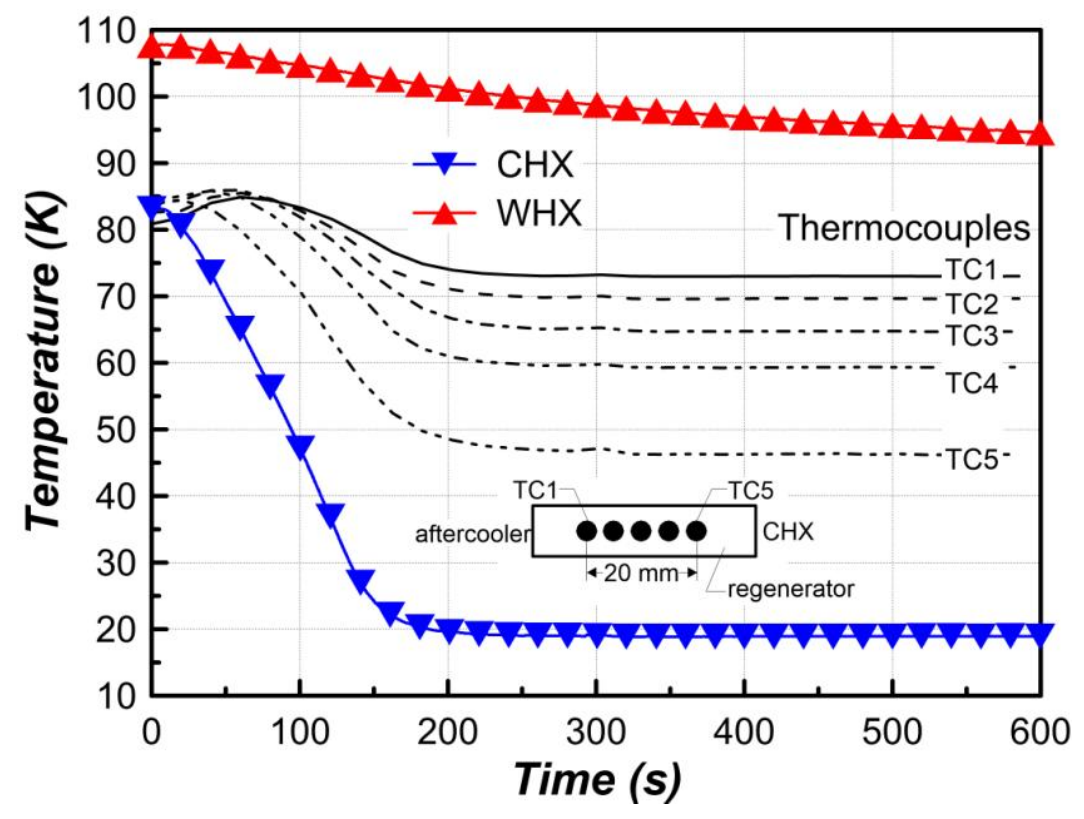

(a)

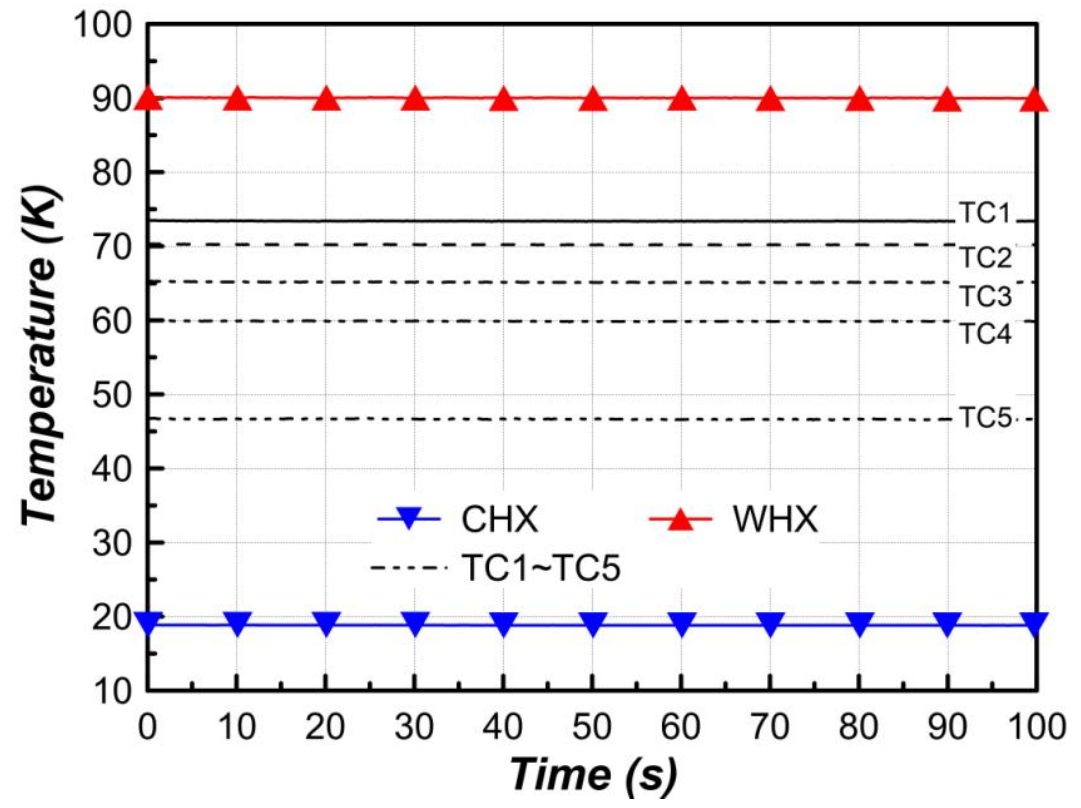

(b)

Fig. 6 (a) Typical cool-down curve at the frequency of $50 \mathrm{~Hz}$ and (b) temperature distribution at the steady-state 


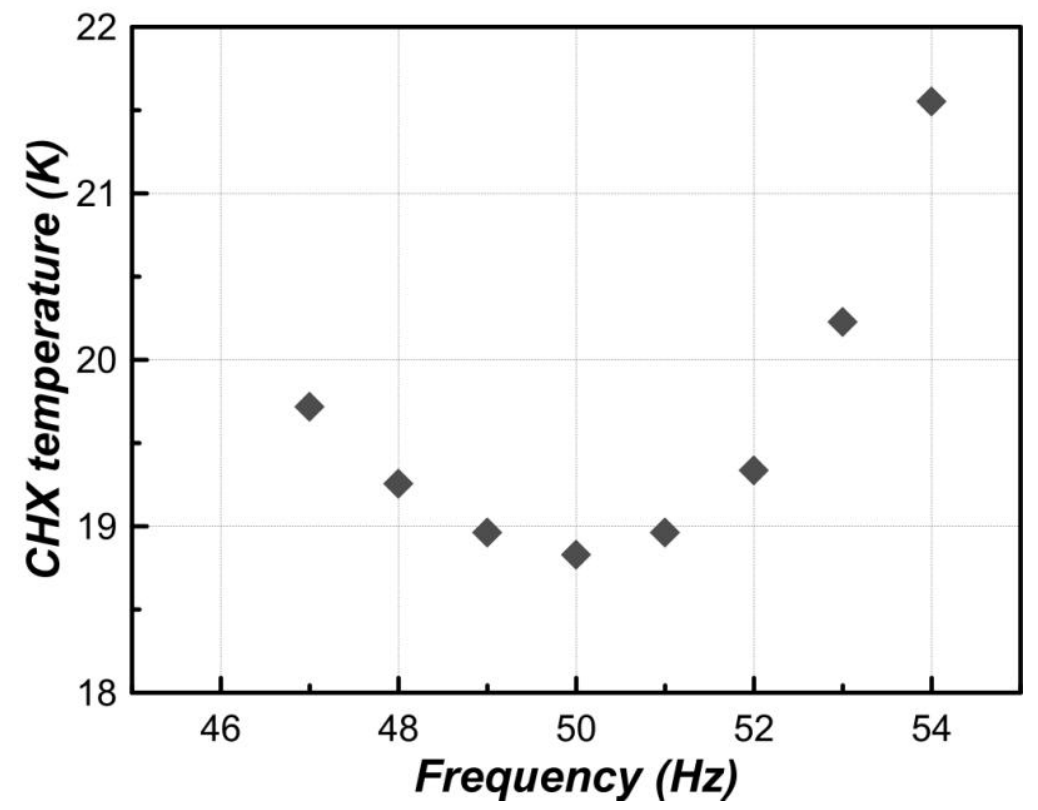

Fig. 7 No-load temperature variation with frequency 


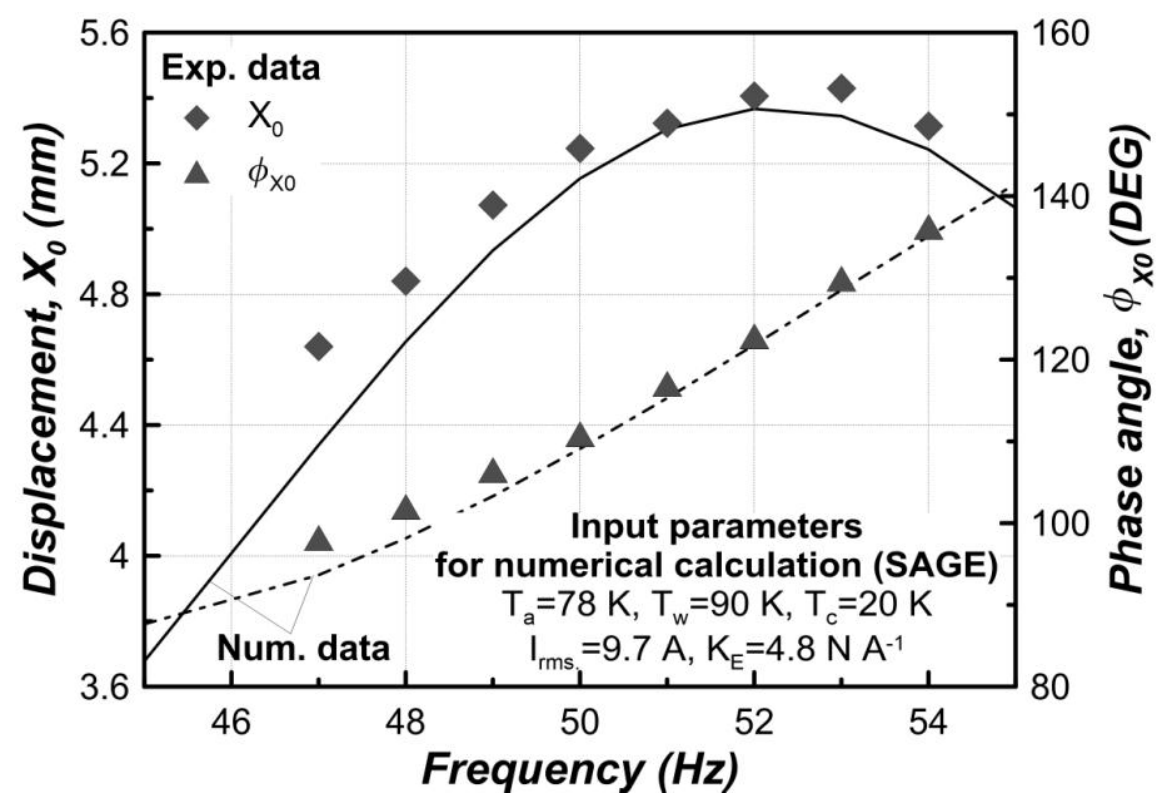

(a)

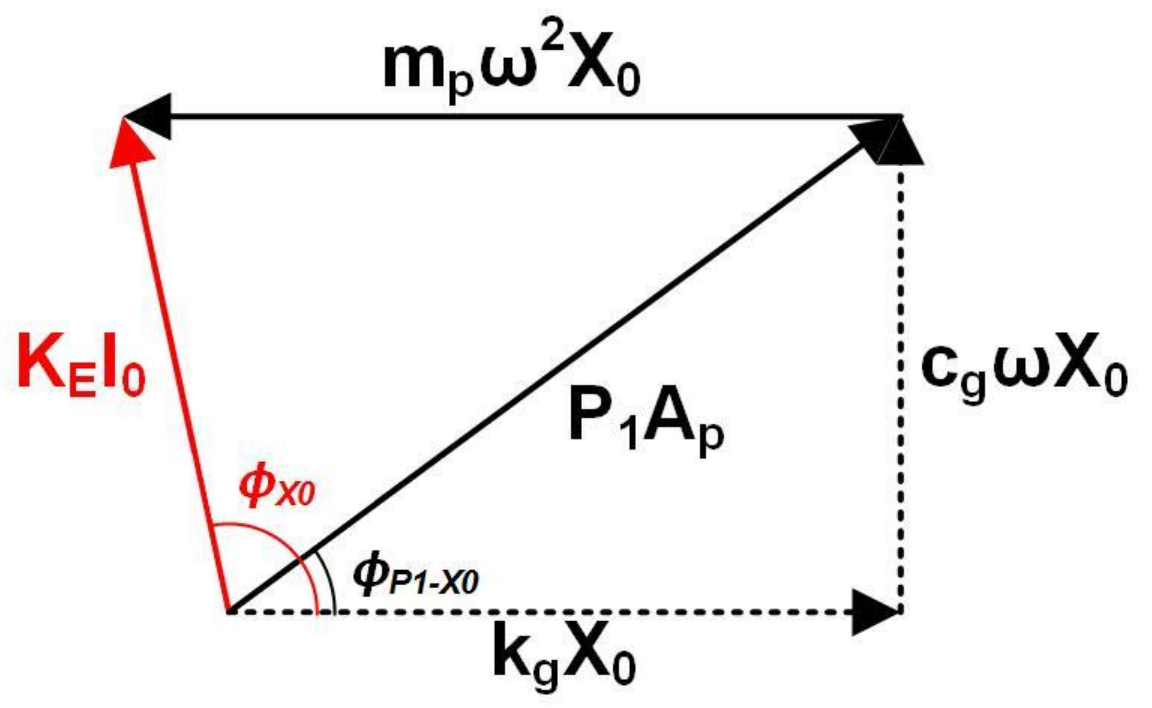

(b) 


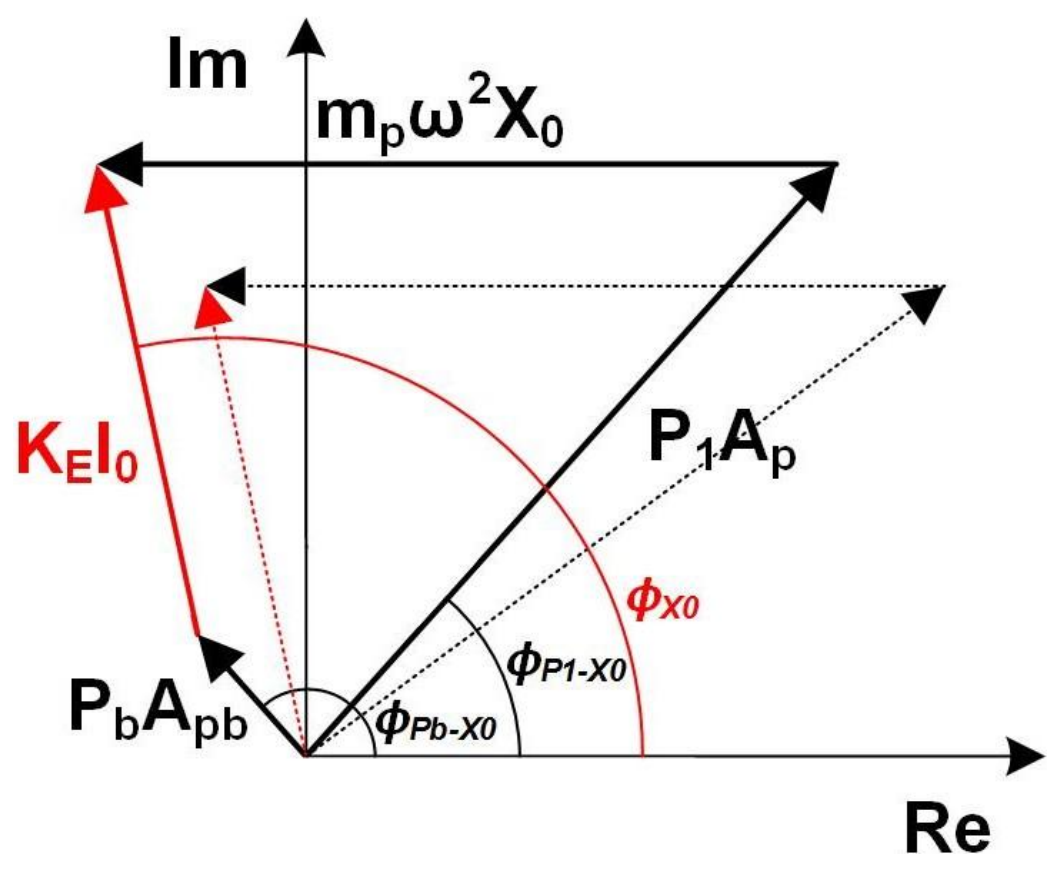

(c)

Fig. 8 (a) Frequency dependency of the piston stroke and its phase angle relative to that of current waveform, (b) phasor diagram for flexure-free linear compressor and (c) phasor diagram for flexure-free linear compressor in consideration of pressure variation within the bouncing volume of linear compressor 


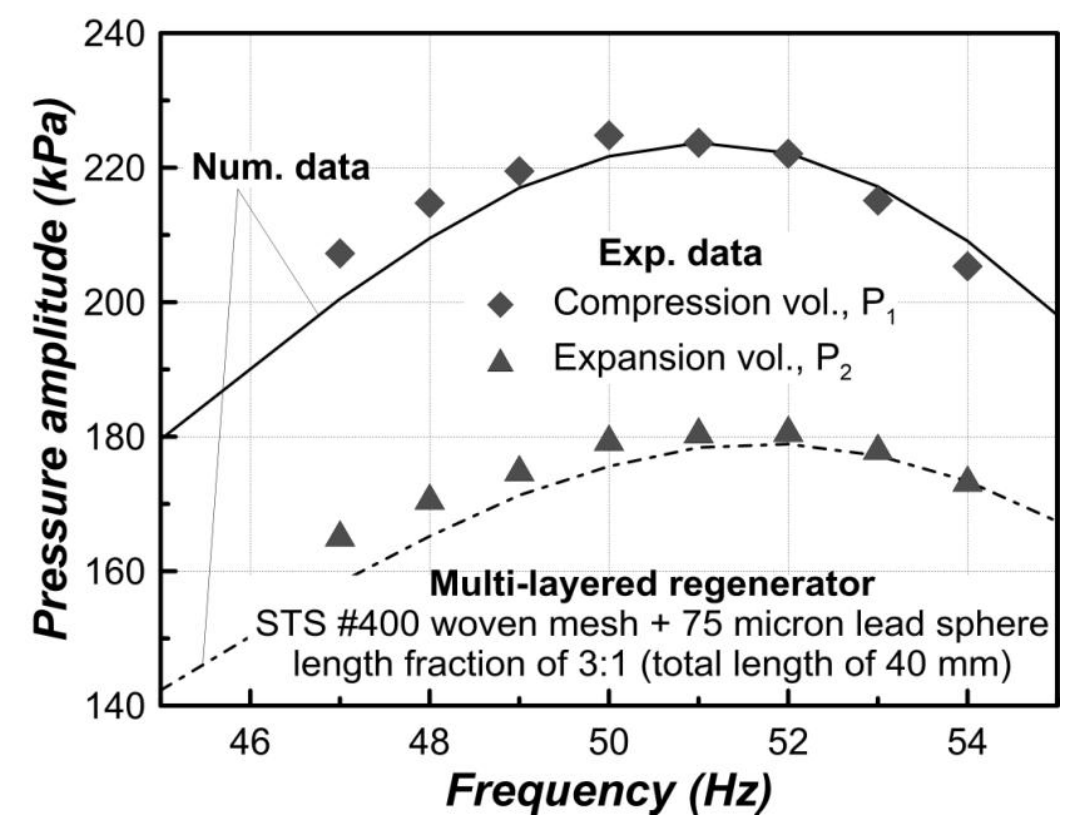

(a)

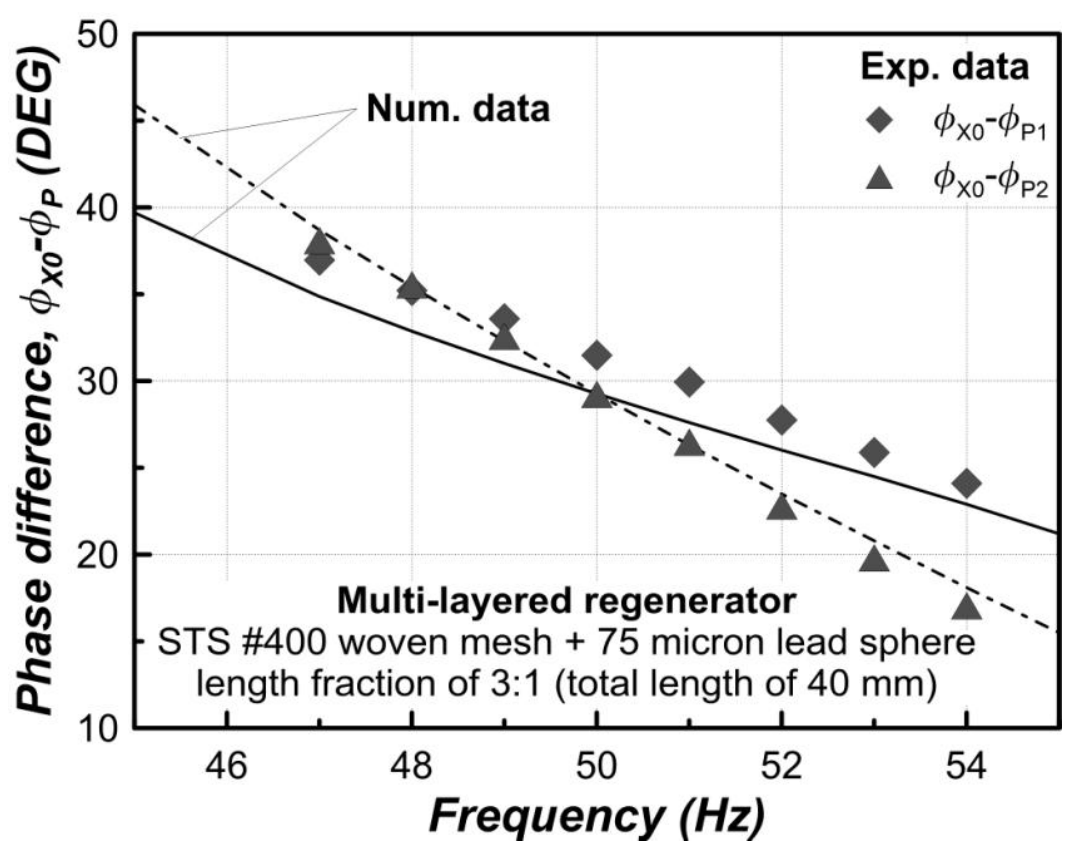

(b)

Fig. 9 Frequency dependency of dynamic pressure (a) amplitude at the compression volume $\left(\mathrm{P}_{1}\right)$ and the cold expansion volume $\left(\mathrm{P}_{2}\right)$ and $(\mathrm{b})$ their phase angle relative to that of piston stroke 


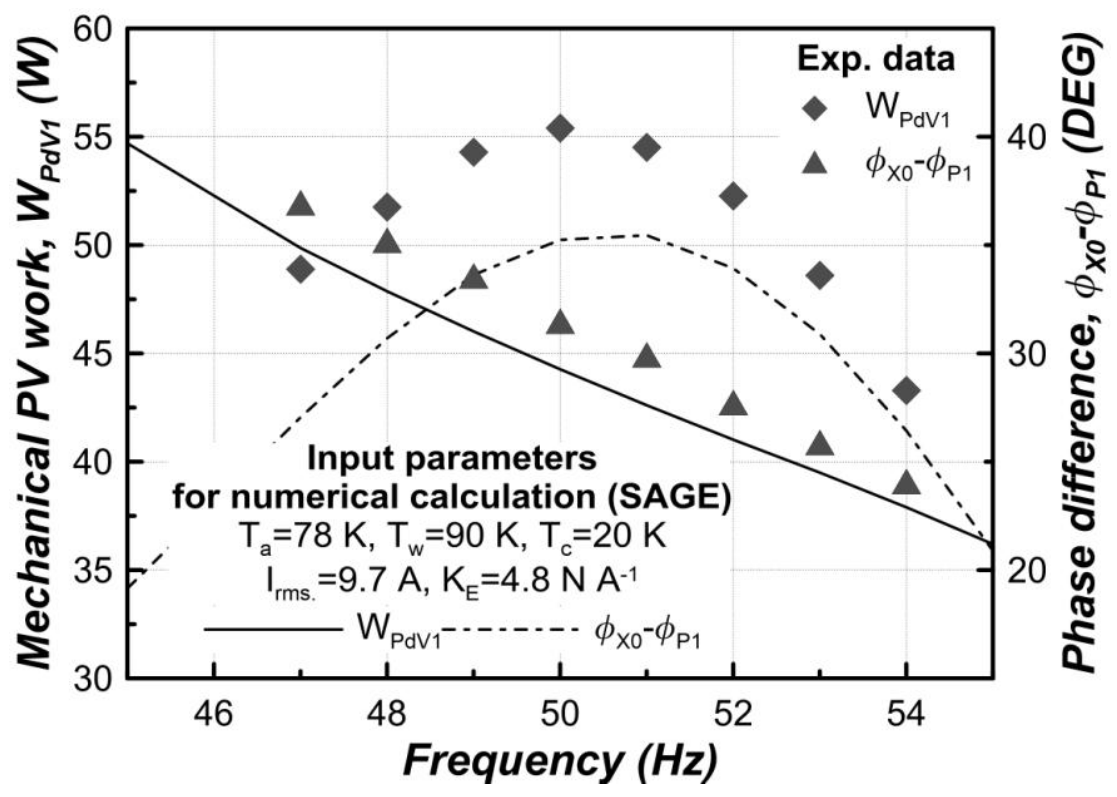

(a)

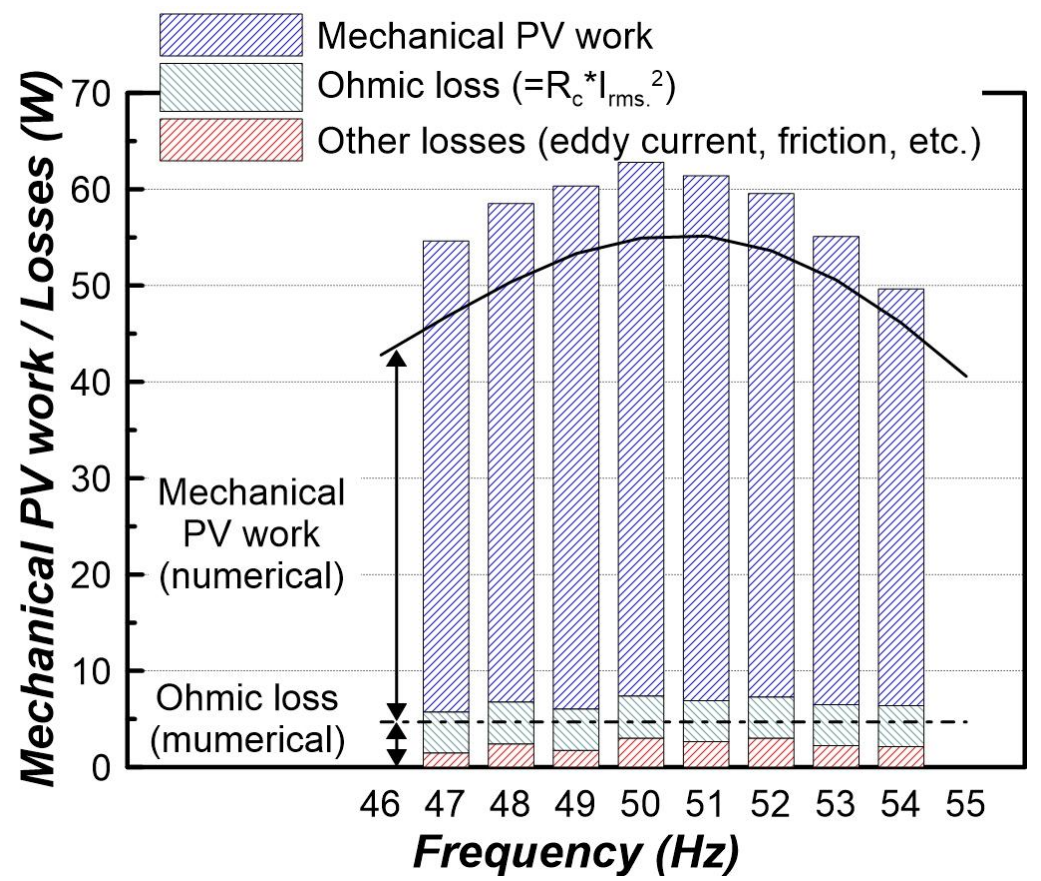

(b)

Fig. 10 Frequency dependency of (a) the mechanical work at the compression volume, the phase difference between the piston stroke and the pressure and (b) the loss mechanisms within the cold linear compressor 


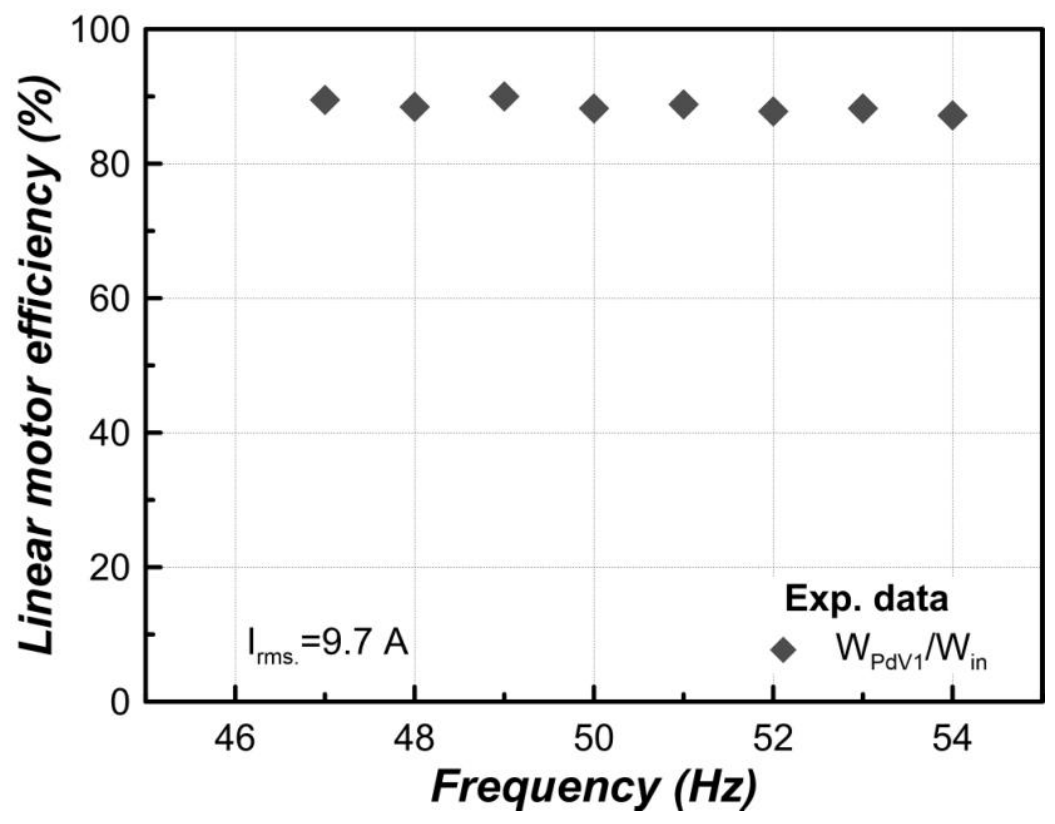

Fig. 11 Compression efficiency with frequency 


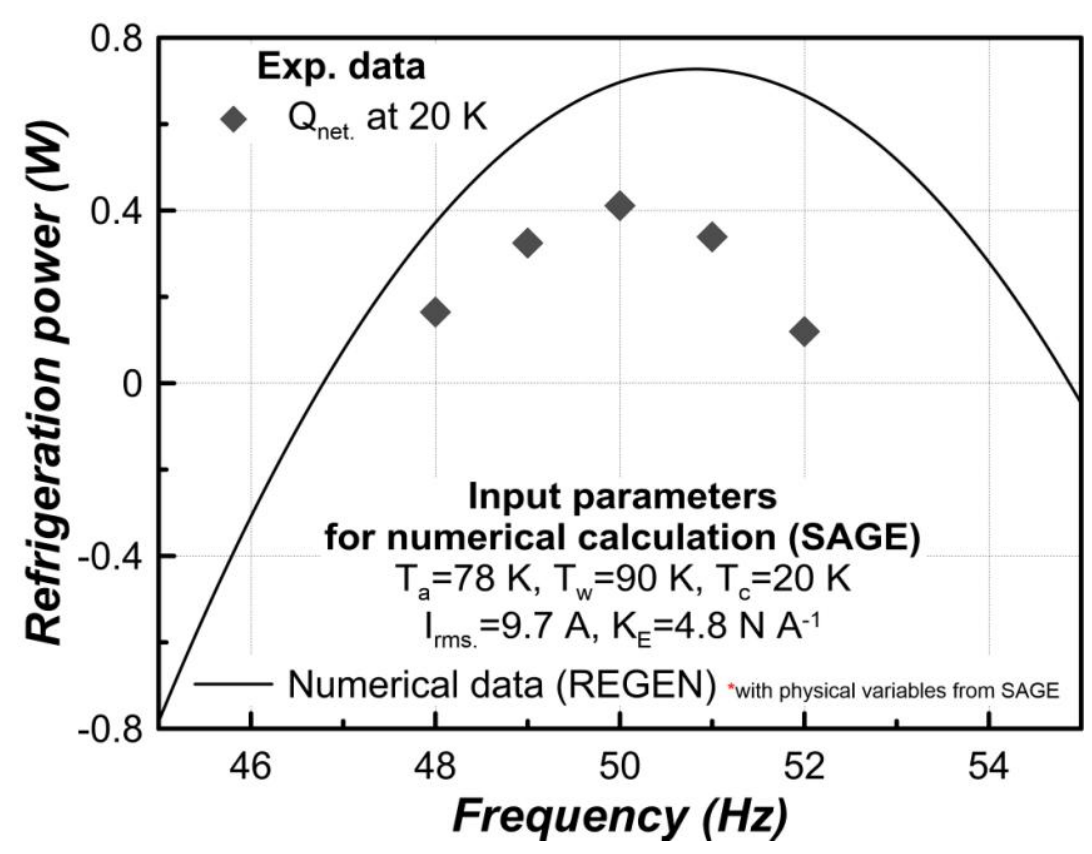

(a)

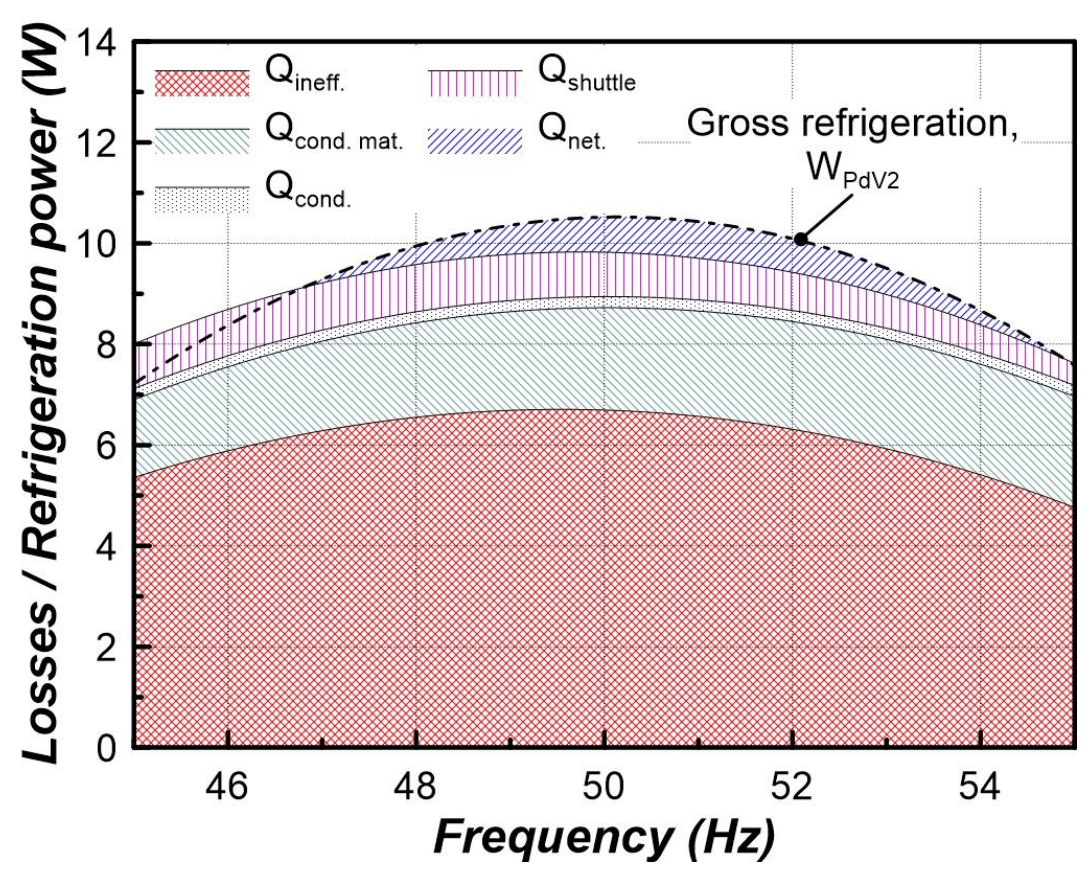

(b)

Fig. 12 Frequency dependency of (a) the net refrigeration power at $20 \mathrm{~K}$ and (b) the loss mechanisms in the whole system at the cold-end 